\title{
3 Researc Square

\section{In-situ Monitoring of Direct Energy Deposition via Structured Light System and its Application in Remanufacturing Industry}

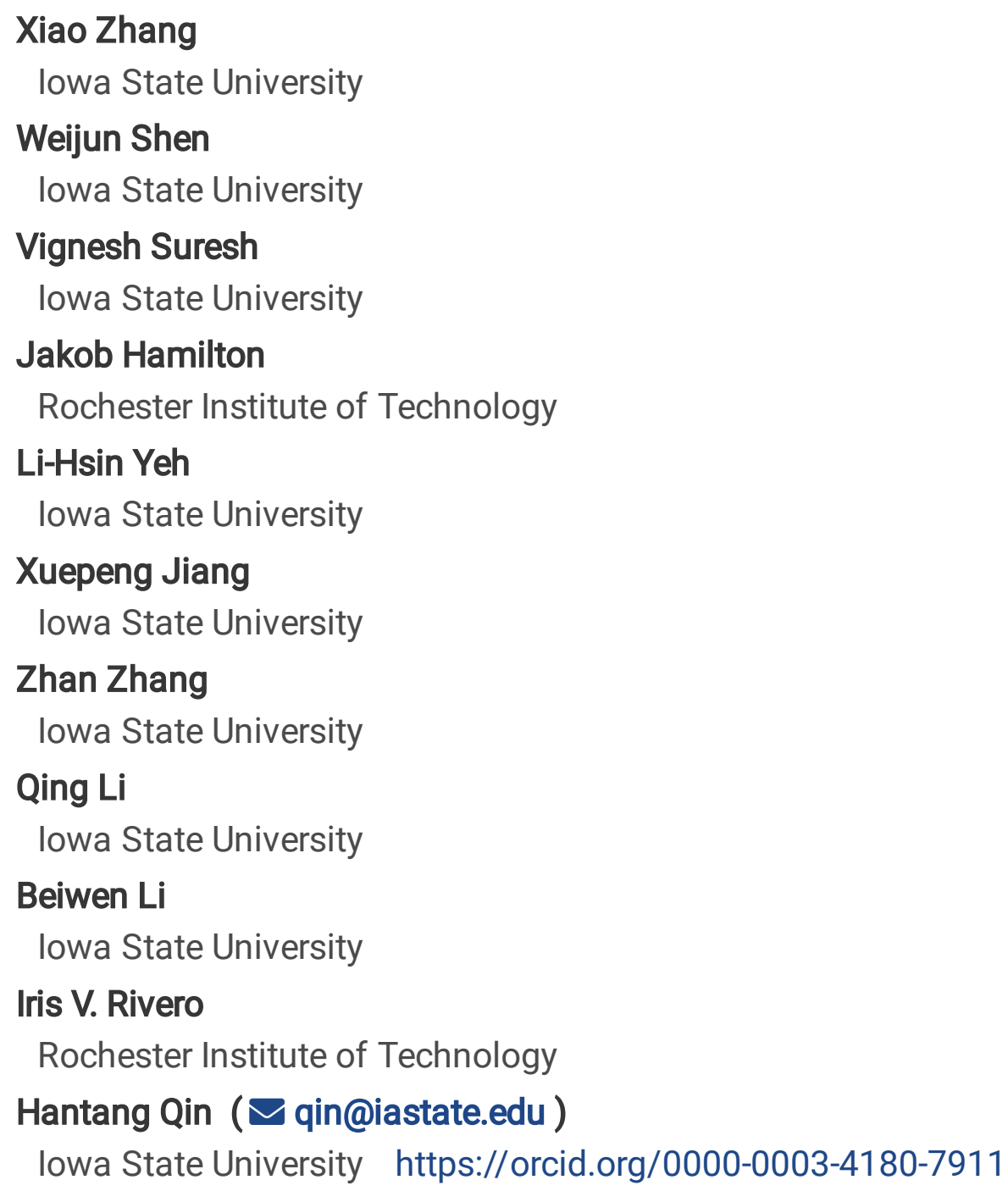

\section{Research Article}

Keywords: direct energy deposition, in-situ monitoring, structured light system, remanufacturing

Posted Date: March 6th, 2021

DOl: https://doi.org/10.21203/rs.3.rs-278338/v1 
License: (c) (i) This work is licensed under a Creative Commons Attribution 4.0 International License. Read Full License 


\title{
In-situ Monitoring of Direct Energy Deposition via Structured Light System and its Application in Remanufacturing Industry
}

Xiao Zhang ${ }^{1}$, Weijun Shen ${ }^{1,3}$, Vignesh Suresh ${ }^{3}$, Jakob Hamilton ${ }^{4}$, Li-Hsin Yeh $^{3}$, Xuepeng Jiang ${ }^{1}$, Zhan Zhang ${ }^{2}$, Qing $\mathrm{Li}^{1}$, Beiwen $\mathrm{Li}^{3}$, Iris V. Rivero ${ }^{4}$, Hantang Qin ${ }^{1,2, *}$

${ }^{1}$ Industrial and Manufacturing Systems Engineering, Iowa State University, Ames, Iowa, 50011 ,USA

${ }^{2}$ Center for Nondestructive Evaluation, Iowa State University, Ames, Iowa, 50011, USA

${ }^{3}$ Mechanical Engineering Department, Iowa State University, Ames, Iowa, 50011, USA

${ }^{4}$ Departmnet of Industrial and Systems Engineering, Rochester Institute of Technology, Rochester, New York, 14623, USA

*Corresponding authors: Hantang Qin, Tel.: +1-515-294-1248. E-mail: qin@iastate.edu

\begin{abstract}
The Direct Energy Deposition (DED) process utilizes laser energy to melt metal powders and deposit them on the substrate layer to manufacture complex metal parts. This study was applied as a remanufacturing and repair process to fix used parts, which reduced unnecessary waste in the manufacturing industry. However, there could be defects generated during the repair, such as porosity or bumpy morphological defects. Traditionally the operator would use a design of experiment (DOE) or simulation method to understand the printing parameters' influence on the printed part. There are several influential factors: laser power, scanning speed, powder feeding rate, and standoff distance. Each DED machine has a different setup in practice, which results in some uncertainties for the printing results. For example, the nozzle diameter and laser type could be varied in different DED machines. Thus, it was hypothesized that a repair could be more effective if the printing process could be monitored in real-time. In this study, a structured light system (SLS) was used to capture the printing process's layer-wise information. The SLS system is capable of performing 3D surface scanning with a high-resolution of $10 \mu \mathrm{m}$. To determine how much material needs to be deposited, given the initial scanning of the part and allowing the realtime observation of each layer's information. Once a defect was found in-situ, the DED machine (hybrid machine) would change the tool and remove the flawed layer. After the repair, the nondestructive approach computed tomography (CT) was applied to examine its interior features. In this research, a DED machine using 316L stainless steel was used to perform the repairing process to demonstrate its effectiveness. The lab-built SLS system was used to capture each layer's information, and CT data was provided for the quality evaluation. The novel manufacturing approach could improve the DED repair quality, reduce the repair time, and promote repair automation. In the future, it has a great potential to be used in the manufacturing industry to repair used parts and avoid the extra cost involved in buying a new part.
\end{abstract}

Keywords: direct energy deposition; in-situ monitoring; structured light system; remanufacturing 


\section{Introduction}

Metal additive manufacturing applies laser power to melt the metal powder and built height in a layer-by-layer manner. It has significant advantages for manufacturing complicated structure parts. Combined with computerized numerical controlled (CNC) methods, the process has been recognized as a hybrid manufacturing approach [1]. Direct energy deposition (DED) printing is one of the most popular metal additive manufacturing approaches. The DED system uses a laser to melt the jetted powder and build three-dimensional geometry on various substrates. It could be used to repair broken or used parts to save costs and contribute to green manufacturing [2]. If there was a defect on a used part, pre-machining and the DED printing could be combined as a hybrid manufacturing approach to repair the part. For example, defective voids in turbine airfoils were repaired by the DED process and evaluated to reduced impact on the environment and energy by life Cycle Assessment [3]. It also can repair parts with materials that differ from the original material of the part. In Germany, Benjamin et al. used a milling tool to remove cracks or damage then applied the DED to deposit Ti$6 \mathrm{Al}-4 \mathrm{~V}$ and stainless steel in the repairing process [4]. The manufacturing of tool dies in the industry has the characteristic of being time-consuming from product design, manufacturing, maintenance, high-cost, and complex manufacturing processes. Leunda et al. [5] demonstrated the effectiveness of repairing dies with CPM $10 \mathrm{~V}$ and Vanadis 4 Extra tool steel powders material by $\mathrm{Nd}$ : YAG laser enabled metal printing process. In the field of manufacturing, it was used to repair defects in Inconel 718 [6]. Bone regeneration and repair is challenging due to the biological and mechanical nature of bone. In the medical area, DED printing has successfully been used for bone repair [7]. In this study, DED printing was used to repair used parts with the novel real-time monitoring system.

Although DED printing has many advantages and applications in multiple disparate areas, the printing results may be influenced by various parameters. Torsten et al. [8] conducted experiments to demonstrate that laser power, velocity, powder mass flow, and spot diameter may result in the different microstructure of Inconel 718 parts. The process parameters may affect the microstructure and the tensile property of printed parts [9]. The effect of building height on mechanical properties and corrosion for austenitic stainless steel $316 \mathrm{~L}$ material was investigated in the DED printing process [10]. Different scanning strategies without shift and rotation between layers resulted in defects with diameters from 100 to $900 \mu \mathrm{m}$ [11]. Before printing on a substrate, Shim [12] found that a slower cooling rate could be achieved by the assistance of preheating when printing highspeed tool steel M4 powder. The variations in these parameters could result in a low-quality part, and the process is unpredictable unless a comprehensive understanding of these parameters is established.

DED printing has various process variables that could influence the printing quality of the manufactured part. It is vital to understand how these parameters influence the quality of printed parts and the optimal strategy to select the printing parameters. However, there is limited research work on understanding how these printing parameters influence DED printing. To improve the quality of metal additive manufactured parts, 
different monitoring methods such as surface quality measurement, sensing, control, and modeling were used to monitor and inspect the printing process [13]. Meanwhile, Elliott [14] pointed out the operator's burden activities, such as finish the part after printing and reset the printing equipment. Thus, it is necessary to develop an in-situ monitoring system to assist the DED printing process and produce high-quality parts. Hofman [15] used a CMOS camera and developed a software algorithm to capture the melt pool's width for compensating disturbances within one second. Craeghs [16] achieved processing rates up to $10 \mathrm{kHz}$ with a highspeed CMOS camera during the in-situ monitoring of the DED printing process. The cooling rate and temperature gradient have an impact on the part quality. Farshidianfar [17] used an infrared thermal imaging system to understand the cooling rate effects and melt pool temperature to monitor 316L stainless steel's microstructure. Modeling strategies were widely used for optimized designs of metal additive manufacturing [18]. A thermo-elastic-plastic model was established by Yang [19] to predict the thermomechanical behavior of Ti-6Al-4V during the DED printing process. An optoelectronic sensor recorded the powder flow rate to achieve a uniform geometry [20]. The optical monitoring system was considered one of the most effective approaches for observing the high scanning speed and melt pool dynamics during the metal additive manufacturing process [21].

Although several methods for monitoring the printing process exist, the structured light system (SLS) has not been used as an optical system to monitor the DED printing process in real-time. The SLS system has highresolution, high-speed, and low-cost characteristics to achieve the 3D scanning of three-dimensional objects. The SLS is an optical system that could capture and reconstruct three-dimensional objects in realtime with an accuracy of $0.2 \mathrm{~mm}$ [22]. The resolution of the SLS system could be adjusted according to various scenarios in the application. In this study, the SLS system was used to monitor the DED printing process, capture the 3D morphology [23] of additive manufactured parts [24] and evaluate measurement results among different optical systems [25-26]. Each printed layer's threedimensional characteristics were captured and stored to optimize printing parameters and repair used parts. Engine heads that have been in service for a long time can develop multiple defects, but it is not economically affordable to remove them from service and replace with new part [27]. Green manufacturing encourages recycling used parts to avoid material waste and possible pollution to the environment [28-29].

This research creates a real-time AM repair system (RAMRS) using a DED machine and an SLS optical system to repair used parts in the manufacturing field. The repair process was presented and demonstrated in this study to prove the effectiveness of this method. First, a DED system was used to repair a used engine head, as shown in Figure 1. Before the repair, the SLS system was used to scan the surface of the used part for locating the position and size information of defects. After that, a corresponding strategy for repairing the engine head was formed. CT scanning was used to capture the repaired sample's interior structure after the repair process.

This study has provided a new optical approach to monitor and assist the re-made manufacturing process. It is assumed that the SLS system could capture each layer's morphology and provide the $0.2 \mathrm{~mm}$ 
resolution during the printing process. The repair quality will be verified based on the surface roughness value and the nondestructive approach's evaluation. This novel method could develop a green, highquality, automated, defects reduced metal additive manufacturing industry.

\section{Materials and Methods}

\subsection{Materials}

The powder material used in this study for DED is 316L stainless steel. The particle size of the spherically shaped powder particle ranges between $1 \mu \mathrm{m}$ and $100 \mu \mathrm{m}$. The material was preheated to $40^{\circ}$ Celsius before the actual printing was initiated [30]. Stainless steel substrate was selected in this study for the printing experiments. The used engine heads were made of cast iron.
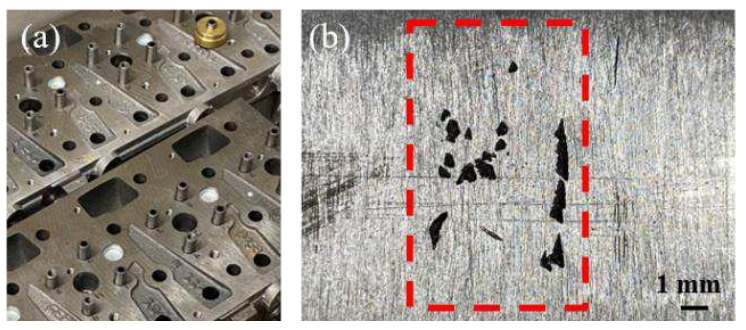

Fig.1 a engine head parts, b sliced engine head with defects on top

\subsection{Mechanism of direct energy deposition}

In this study, a hybrid manufacturing machine was used for the repair process. The 316L stainless steel powder was stored in the material chamber and sent out through a controlled disk system. During printing, the powder flows onto the substrate and is melted simultaneously by a laser. Melted SS powder was deposited layer by layer and rapidly cooled down in a solid-state as the laser moves away.

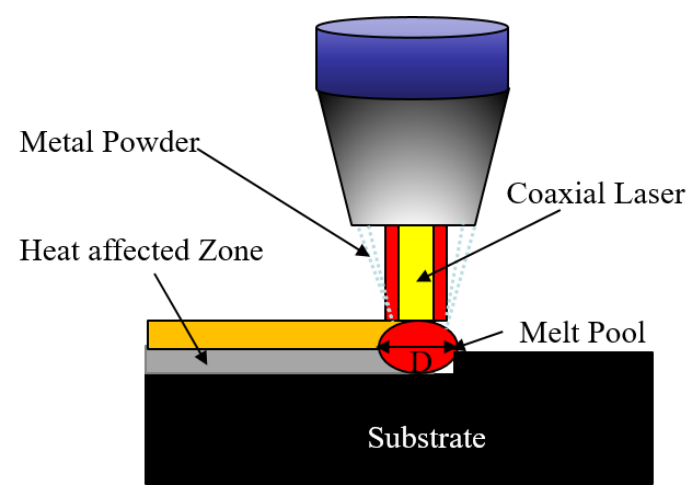

Fig.2 A schematic diagram of the DED process

As shown in Figure 2, the material was melted and deposited on the metal substrate to form a specific shape as the printer head moved at a plotting speed $\mathrm{v}$. The bead size of the DED printer was $1 \mathrm{~mm}$. This printing process was controlled by the laser recipe, plotting speed, and standoff distance. The gcode program controlled the plotting speed and distance between the nozzle head and substrate.

Equation (1) describes the quantitative relationship between the effective absorption rate and temperature [31]. This function represents the ratio of the energy for heating the specimen T_H vs. laser irradiation E_L energy input. The energy used to heat the specimen started with a temperature T_0 and ended with temperature $T_{-} 1$. $P$ is the nominal laser power, $\mathrm{v}$ is the scanning speed, and $\mathrm{l}$ is the laser track's total length during the printing.

$$
A_{\text {eff }}=\frac{E_{H}}{E_{L}}=\frac{\int_{T_{0}}^{T_{1}} m c_{p}(T) d t}{P\left(\frac{l}{v}\right)}
$$

\subsection{In-situ monitoring system}

The printing process was observed and monitored by the SLS system in real-time. The SLS system consists of a camera C1, a 
projector P1, and control systems. The projector projects fringe patterns on the target

(a)

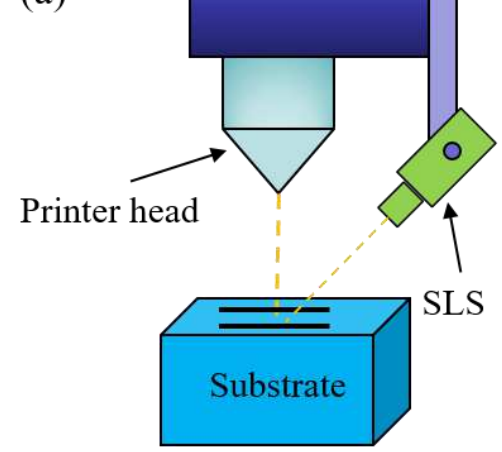

(b)

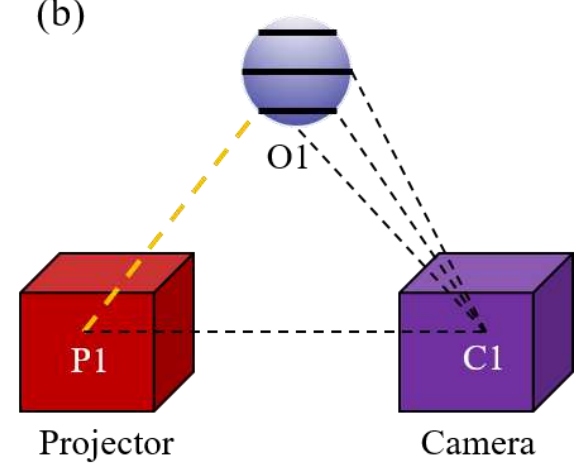

Fig.3 a Setup, b mechanism of the SLS system

object's surface while the camera captures the fringe patterns. Using the captured fringe images and the calibration information, the $3 \mathrm{D}$ surface can be reconstructed [32]. The 3D data from SLS will be in point cloud data format. This system's resolution is $10 \mu \mathrm{m}$ and has a field of view of $12 \mathrm{~mm}$ by $12 \mathrm{~mm}$.

The surface point cloud data was used in this study to reflect the surface quality and quantitative change of surface roughness as the layer was building up. Before the printing, the SLS system was used to scan the part surface to determine the shape, location, and volume of defects. This information will be used for the programming of the g-code to pre-machine and repair the defect area. During the printing process, the SLS system will capture the point cloud data of each layer. This operation enables the operator to monitor the possible abnormal defects during the printing process, such as bumpy morphology or porosity. If any defects are found in the process, the hybrid DED printer could use the milling tool to remove the defect layer and print a new layer to replace it.

\section{$2.4 \mu-C T$ measurement}

$\mu$-CT data for DED was taken with a lab-built $\mathrm{X}$-ray radiography system (see Fig. 4) consisting of the X-ray source, rotation/translation stage, panel detector, control system, and reconstruction system.

During the measurement process, the specimen was illuminated by a cone-beam Xray source. After the X-ray transmitted the specimen and was partially absorbed, the remaining X-ray was collected by a flat-panel detector and converted into grayscale data according to the residual intensity. The sample was rotated by $360^{\circ}$, and a series of two-dimensional grayscale data was taken for further reconstruction.

The system parameter settings and the individual settings for each sample are listed in Table 1.

After the CT scanning, the original raw data will be reconstructed with lab-built software. All samples are reconstructed into $1000 \times 1000 \times 1000$ volume data, where each voxel contains 16-bit grayscale information. In this work, surface data is also segmented besides internal defects inspection. Volume 
data cannot directly reflect the "surface," so it is required to localize all the voxels on the "surface."

Table 1 CT system settings

\begin{tabular}{|c|c|c|c|}
\hline Parameter & \multicolumn{3}{|c|}{ Value } \\
\hline Source to detector distance & \multicolumn{3}{|c|}{$1228 \mathrm{~mm}$} \\
\hline Filter material & \multicolumn{3}{|c|}{ Copper } \\
\hline Filter thickness & \multicolumn{3}{|c|}{$1 \mathrm{~mm}$} \\
\hline Number of projections & \multicolumn{3}{|c|}{360} \\
\hline Detector pixels & \multicolumn{3}{|c|}{$2048 \times 2048$} \\
\hline Detector pixel pitch & \multicolumn{3}{|c|}{$200 \mu \mathrm{m}$} \\
\hline Spatial Resolution & \multicolumn{3}{|c|}{$2.5 \mathrm{lp} / \mathrm{mm}$} \\
\hline \multicolumn{4}{|l|}{ Table 2} \\
\hline Sample No. & S1 & S2 & S3 \\
\hline Source to target distance & $114 \mathrm{~mm}$ & $114 \mathrm{~mm}$ & $105 \mathrm{~mm}$ \\
\hline Voxel size & $38.1626 \mu \mathrm{m}$ & $38.1626 \mu \mathrm{m}$ & $35.8741 \mu \mathrm{m}$ \\
\hline Acceleration voltage & $200 \mathrm{kVp}$ & $225 \mathrm{kVp}$ & $200 \mathrm{kVp}$ \\
\hline Filament current & $510 \mu \mathrm{A}$ & $400 \mu \mathrm{A}$ & $650 \mu \mathrm{A}$ \\
\hline
\end{tabular}

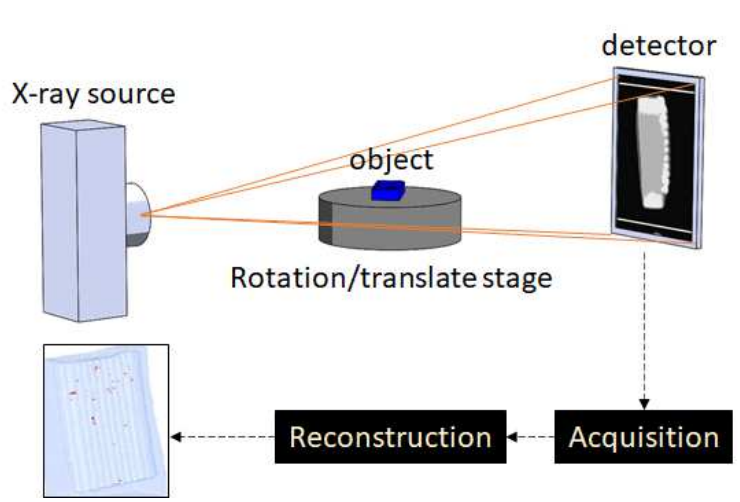

Fig.4 Schematic of the CT system

\subsection{Point cloud data processing}

The segmentation process identifies every voxel if it belongs to the target or the background converting grayscale CT volume into a form that allows quantitative characterization. The methods applied to volume data segmentation generally originate from expanding image segmentation methods to higher dimensions. Image segmentation methods can be divided into two categories, global thresholding, and locally adaptive segmentation. Global thresholding generally sets a fixed threshold value to separate the entire CT volume based 
on the histogram of voxels with grayscale intensity (see Fig. 5a). Local adaptive segmentation makes segmentation decisions
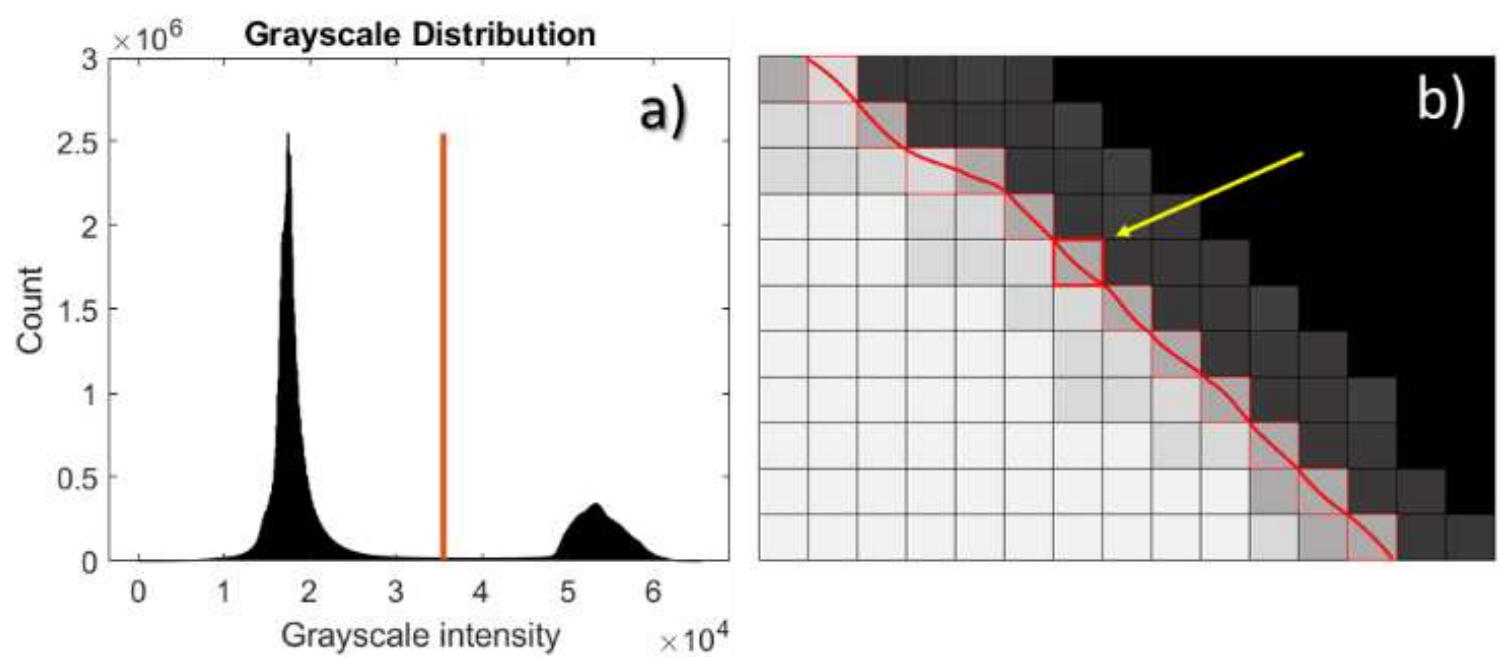

Fig.5 Simplified representation of two segmentation methods a global thresholding based on the grayscale histogram, b locally adaptive method test each pixel with its neighbours

for each voxel based on itself and its neighbors' gray value (see Fig. 5b).

Global segmentation is fast and straightforward, but it is easily affected by artifacts (see Fig. 6a, b). On the other hand, local adaptive segmentation is timeconsuming but performs better (see Fig. 6c).

Locally adaptive segmentation generally can separate the foreground with the background well, but not enough for surface extraction, especially for the irregular surfaces (see Fig. 7a,b). In this work, a combination of CL-Ridler thresholding[17] and locally adaptive segmentation method[18] with local contrast enhancement is applied for surface segmentation (see Fig. $8 c)$. After extracting the surface, it will be converted into the same $3 \mathrm{D}(\mathrm{x}, \mathrm{y}, \mathrm{z})$ form as SLS (see Fig. 8).
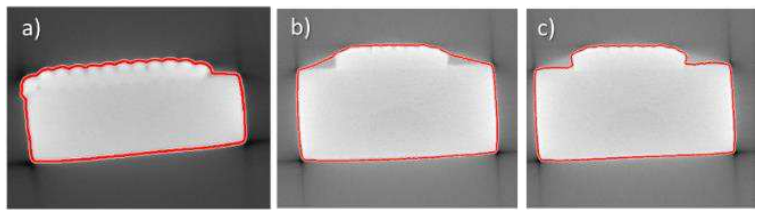

Fig.6 CT slice images processed with different methods, a global thresholding, $\mathbf{b}$ a CT slice with scatter artifacts processed with global thresholding, c slice with scatter artifacts processed with locally adaptive segmentation 


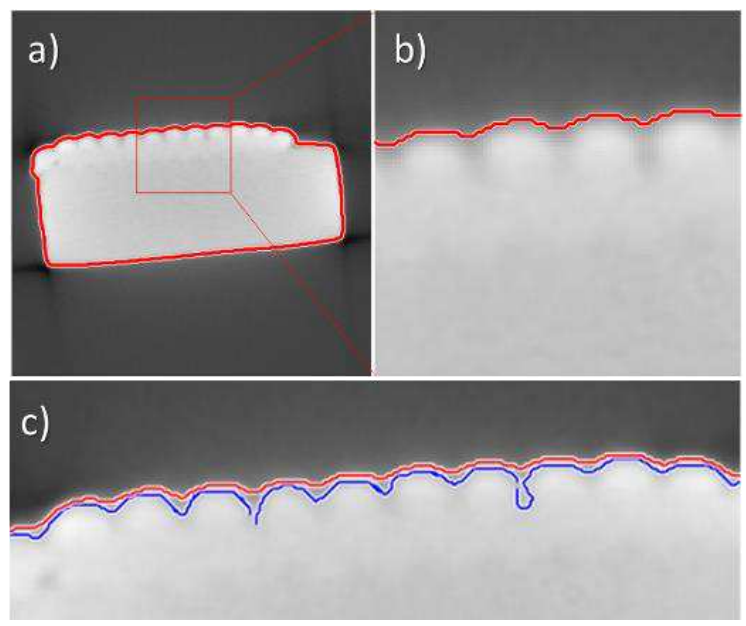

Fig.7 Segmentation of surface from CT data, a applied with locally adaptive segmentation, b zoom-in figure of Fig. 8a, c segmentation comparison between the locally adaptive method (red contour) and the proposed approach (blue contour)

An iterative closest point (ICP) algorithm $[19,20]$ is applied to align the surface datasets from SLS and CT systems.

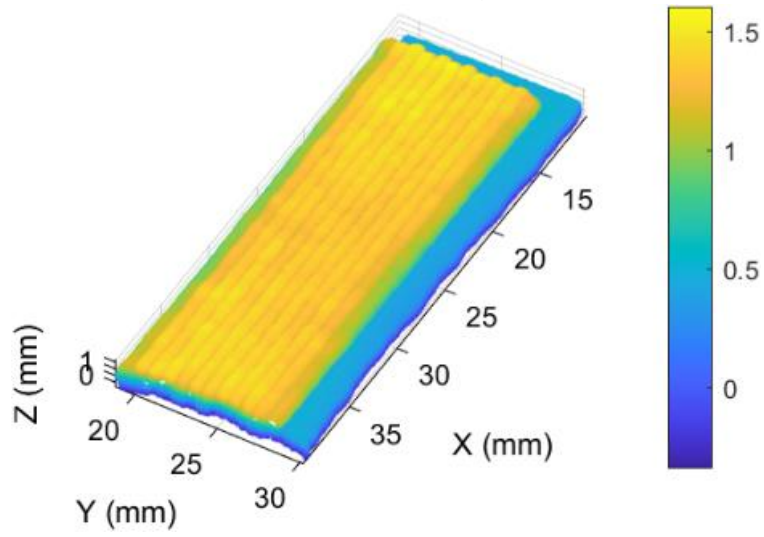

Fig.8 Surface extracted from CT data

The resolutions of the camera of SLS and the detector of the CT system are different. So a common region of interest is set, and all the points outside this region are removed to trim the surfaces into the same size.

\subsection{Data comparison between CT and SLS system}

After completing the alignment and trimming, the similarity of the two sets of data needs to be checked to ensure that the surface data from the CT is capable of subsequent operations. Three methods are applied to test the correlation between the two datasets: areal surface texture parameter, cloud comparison methods, and a statistical method.

The arithmetical mean height of area roughness (S_a), and the root mean square height of area roughness (S_q) are first used to evaluate the two datasets.

$S_{a}$, and $S_{q}$ can be described as follows,

$$
\begin{aligned}
S_{a} & =\frac{1}{M \times N} \sum_{i=1}^{M} \sum_{j=1}^{N}\left[Z\left(x_{i}, y_{j}\right)\right] \\
S_{q} & =\sqrt{\frac{1}{M \times N} \sum_{i=1}^{M} \sum_{j=1}^{N}\left[Z\left(x_{i}, y_{j}\right)\right]^{2}}
\end{aligned}
$$

where $M$ and $N$ are the numbers of data points in $X$ and $Y$ axis correspondingly, and $Z\left(x_{i}, y_{j}\right)$ is the height variation.

The regional surface roughness can quickly compare the average or root-meansquare height variations of two surfaces. However, a consistent surface roughness does not mean that the two surfaces are similar.

A method that can take into account the degree of fit of each point needs to be applied. Since the two datasets are in the form of 3D $(\mathrm{x}, \mathrm{y}, \mathrm{z})$, point-cloud comparison methods are used.

$\mathrm{C} 2 \mathrm{C}$ is a 3D comparison method of pointclouds, which is fast and straightforward. This method finds the nearest point in Surface 2, corresponding to each point in Surface 1, and calculates the absolute distance between them (see Fig. 9). 


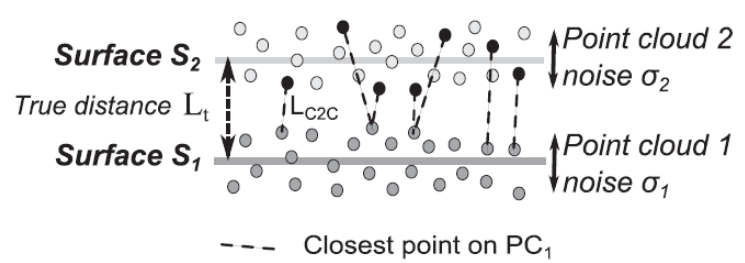

Fig.9 Schematic of C2C method [21]

The variation between two surface datasets is calculated by the distance between the point-cloud from Surface 1 and the reference mesh constructed by Surface 2 (see Fig. 10).

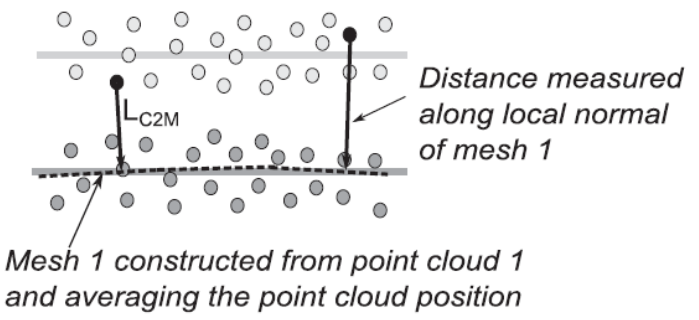

Fig.10 Schematic of C2M method [21]

In the M3C2 process, the core point is firstly subsampled from the reference pointcloud. For any given core point i, a normal vector is defined for each cloud by fitting a plane to the neighbors of that cloud within a radius $\mathrm{D} / 2$ of $\mathrm{i}$. Then a cylinder with diameter $\mathrm{d}$ is centered on the core point $\mathrm{i}$ and projected along the normal vector N_i. After that, the distance between the two point-clouds' average positions is calculated (see Fig. 11) [21].

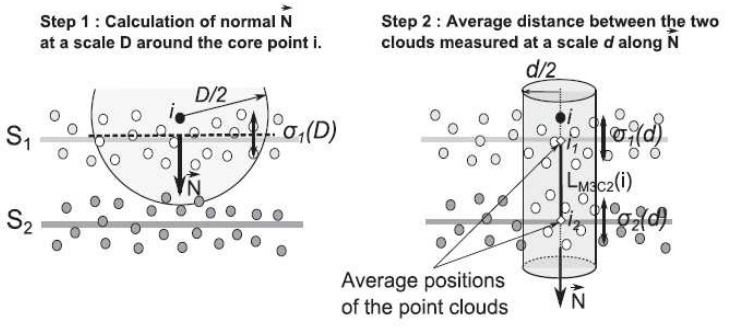

Fig.11 Schematic of M3C2 method [21]

Pearson correlation coefficient is widely used to measure the linear correlation between two variables $\mathrm{X}$ and $\mathrm{Y}$. The value $\mathrm{r}$ of PCC ranges from -1 to +1 . A value of +1 means the two variables are perfectly positively correlated, a value of 0 means there is no association, and a value of -1 represents a perfectly negative correlation.

For the PCC measurement of the two surface data, they are first gridded into depthcoded images. Through connecting each row, the matrices can be rearranged into two $\mathrm{M} \times \mathrm{N}$ vectors, which are denoted as I1 and I2. To compare two matrices, the two vectors are generated in this way, and the PCC can be calculated as a metric of similarity of the two generated vectors[22]. The PCC is calculated as:

$\frac{\sum_{i=1}^{M \times N}\left(I_{1, i}-\overline{I_{1}}\right)\left(I_{2, i}-\overline{I_{2}}\right)}{\sqrt{\sum_{i=1}^{M \times N}\left(I_{1, i}-\overline{I_{1}}\right)^{2}} \sqrt{\sum_{i=1}^{M \times N}\left(I_{2, i}-\overline{I_{2}}\right)^{2}}}$

\subsection{The RAMRS repair framework}

Figure 12 shows the complete repair process, starting from SLS scanning of the defect sample to the nondestructive evaluation of the fixed part. The process starts by determining the dimension of the defect by scanning with the SLS system.

The depth of the defect is the milling depth for pre-machining. The pre-machining process could clean the surface, remove extra material for high-quality repair. The defects' location will enable the hybrid DED machine to find the starting point and volume deposited material. The repair process will consist of printing multilayer 316L stainless steel powder onto the substrate. There exist uncertainty during the printing of each layer. Thus, the SLS system will scan each layer in real-time to monitor the repair quality. However, each layer of the deposited material varies in thickness. Porosity defects may exist inside the layer. Thus, after the repair was finished, a post nondestructive 
evaluation method-computer tomography (CT), was deployed to examine the repaired part's interior quality.

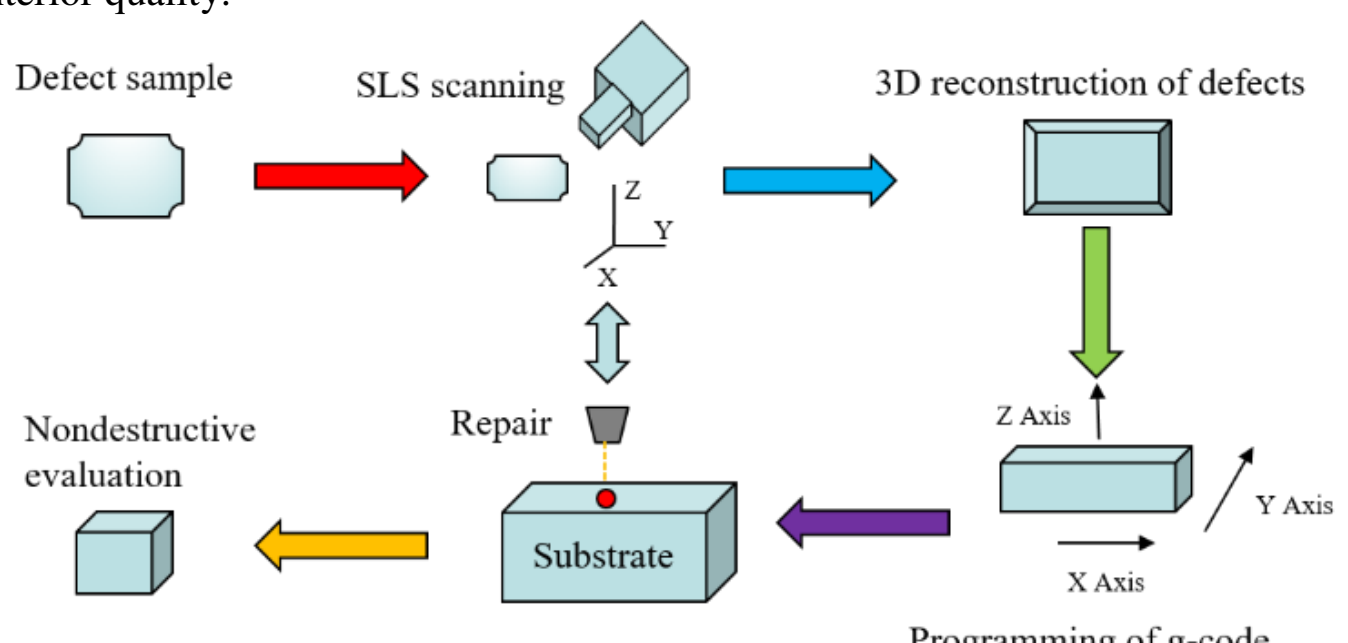

Fig.12 Repair framework of used parts

\section{Results and Discussion}

\subsection{DED printing results}

Table 3. The values of printing parameters in this study. There are two factors: Scanning speed (3 levels) and Recipe (4 levels). The standoff distance was $5 \mathrm{~mm}$, and the nozzle diameter is $1 \mathrm{~mm}$.

\begin{tabular}{cccc}
\hline $\begin{array}{c}\text { Scanning } \\
\text { speed } \\
\text { (inch/minute) }\end{array}$ & $\begin{array}{c}\text { Standoff } \\
\text { distance }(\mathrm{mm})\end{array}$ & $\begin{array}{c}\text { Nozzle } \\
\text { diameter }(\mathrm{mm})\end{array}$ & $\begin{array}{c}\text { Recipe } \\
\text { (Level) }\end{array}$ \\
\hline $\mathbf{7 . 8 7}$ & 5 & 1 & $\mathbf{1}$ \\
$\mathbf{2 3 . 6 2}$ & 5 & 1 & $\mathbf{2}$ \\
$\mathbf{3 9 . 3 7}$ & 5 & 1 & $\mathbf{3}$ \\
& 5 & 1 & $\mathbf{4}$ \\
\hline
\end{tabular}

The DED printed parts were manufactured on a stainless steel substrate. The successful printing of one line pattern on the substrate under selected printing parameters is considered a filament. Different printing parameters influenced the dimension of printed filaments. This nature of the DED system enables repairing different defects, considering the repair efficiency and accuracy. For example, a higher laser energy recipe could repair parts with large defects to save time. For small defects, smaller filaments shall be generated for the repair.

Different filaments with various dimensions were fabricated, as shown in Figure 13 (a). These filaments were fabricated on the stainless steel substrate. It could be seen that different filaments have different colors due to the influence of different recipes. The temperature and powder feeding rate defined the Recipe. The melting temperature could result in a different color of deposited stainless steel material.
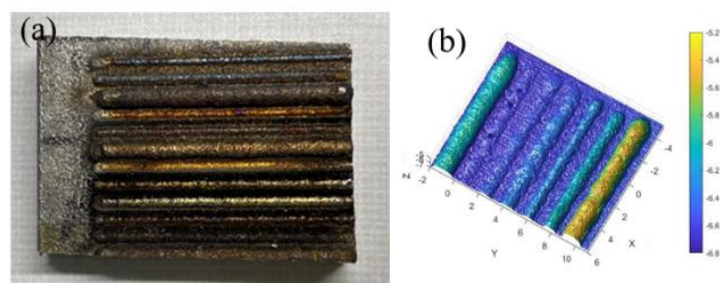

Fig.13 a A 3D printed sample with different scanning speed, powder feeding rate, and laser power, b scanned sample (unit: $\mathrm{mm}$ ) 
The material started to cool down at different temperatures, which generated different oxidized layers that reflected various colors. There are several constant parameters for the printing process: the standoff distance is 5 $\mathrm{mm}$, and the powder feeding rate is 5 grams/minute.

It was shown in Table 3 that there were three levels of the scanning speed of the DED printer head, and there were four levels of the Recipe to define the energy and powder feeding rate. Figure 13(a) shows the 12 filaments fabricated on a stainless steel substrate under 12 treatment conditions.

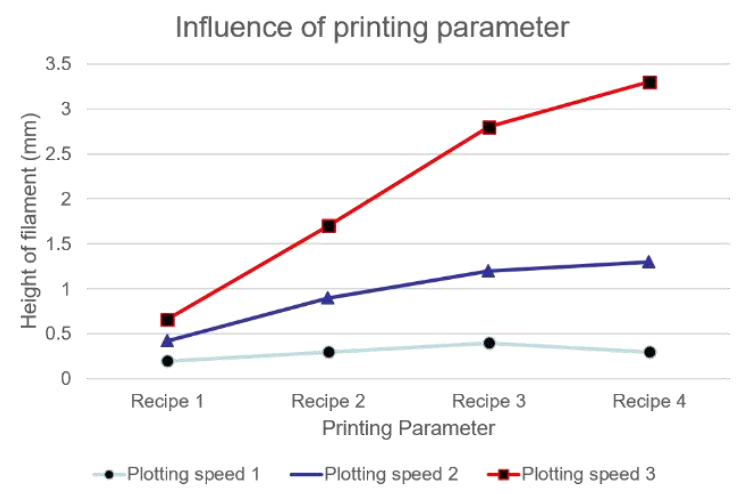

Fig.14 DED printed filaments with different treatment combinations of scanning speed and powder feeding rate

The dimensions of printed filaments have exhibited significant differences, which were influenced by these printing parameters. To understand the relationship between the printing parameters and the size of filaments. The SLS system was used to scan the surface of the printed sample. In Figure 13(b), these filaments were shown different sizes and colors. The color represents the height of each point; yellow color points are the highest points. Figure 14 showed the quantitative relationship between printing parameters and the height of the deposited material. Under the same Recipe, filament height increases with the decrease of plotting speed from 39.37 inch/minute to 7.87 inch/minute. Because of the increased speed, less material could be deposited on the same spot of the substrate in the same amount of time. The filament increases with the change of Recipe. From Recipe 1 to Recipe 4, the powder feed rate has increased together with laser power, which deposited more material onto the substrate.

\subsection{Layer-wise point cloud results}

Multilayer printing is of paramount importance for the repair of used parts. It is not common to repair parts with only one layer of printing; These experiments were performed to print three four-layer samples on the stainless steel substrate. However, new challenges appear for multilayer printing beyond those related to single-layer printing, such as monitoring each layer's printing quality and identifying possible defects inside the printed sample. The in-situ data collection process was deployed to capture the surface point cloud data of each layer.
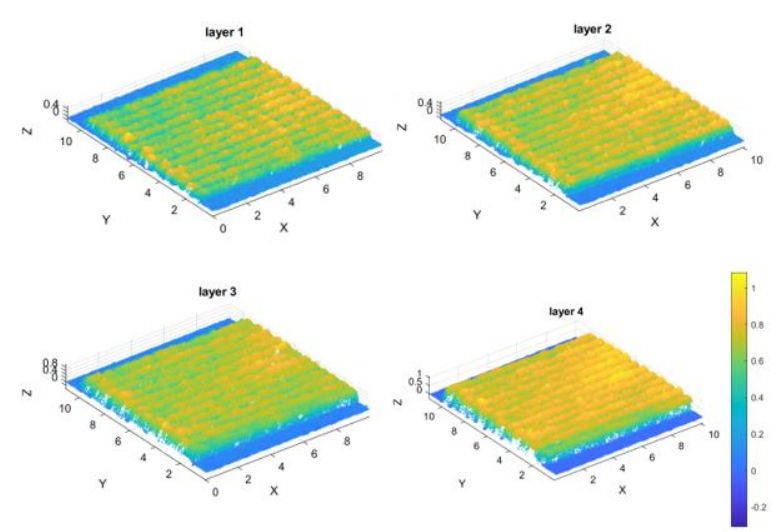

Fig.15 SLS images of each layer of the DED printed sample1 (unit: $\mathrm{mm}$ )

The SLS system was mounted inside the hybrid DED printer for collecting data in real-time. The SLS images of each printed layer were taken to characterize the evolution of the surface roughness. The SLS was 
deployed to capture the surface information in the same area after printing each layer. The captured data was visualized in Matlab using color to represent each point's height information on the surface. In Figure 15, 16, and 17 , the surface point cloud data of each layer could be seen. It was evident from the surface color that each layer has a uniform height and smooth surface roughness. The thickness of this printed sample is around 1 $\mathrm{mm}$ from the measurement results of the SLS system.
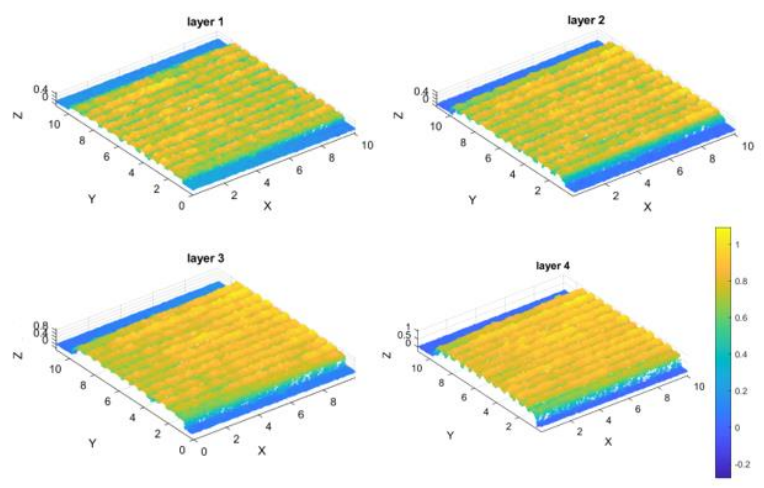

Fig.16 SLS images of each layer of the DED printed sample 2 (unit: $\mathrm{mm}$ )

However, it is still unknown how the surface roughness of each layer evolved. Thus, this study used the Sa parameter to calculate the area roughness of deposited material on each layer. Sa was measured by calculating the difference in each point's height compared to the arithmetical mean of the surface, considering all points on the same scanned area in each layer. In these three experiments, the surface roughness values are maintained between 44.25 and $81.75 \mu \mathrm{m}$.
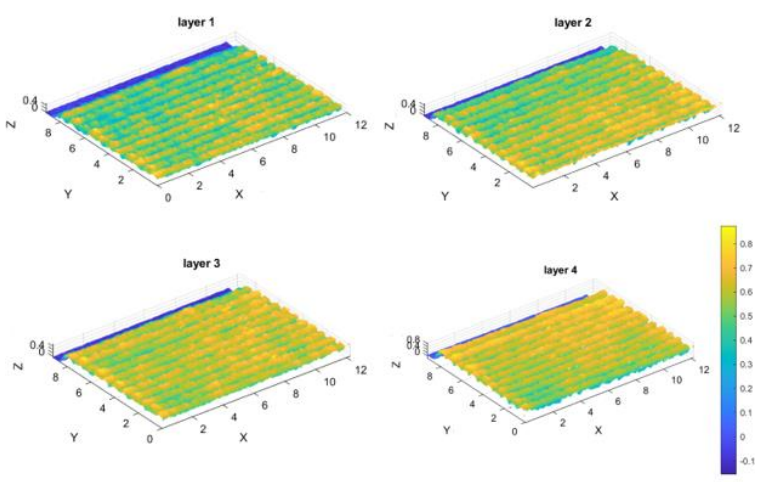

Fig.17 SLS images of each layer of the DED printed sample 3 (unit: $\mathrm{mm}$ )

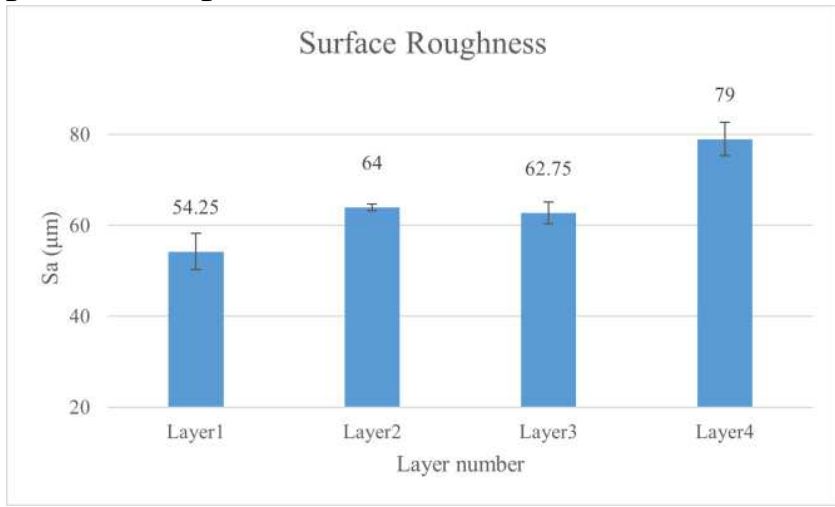

Fig.18 The surface roughness of each layer by DED fabrication sample 1 (unit: $\mu \mathrm{m}$ )

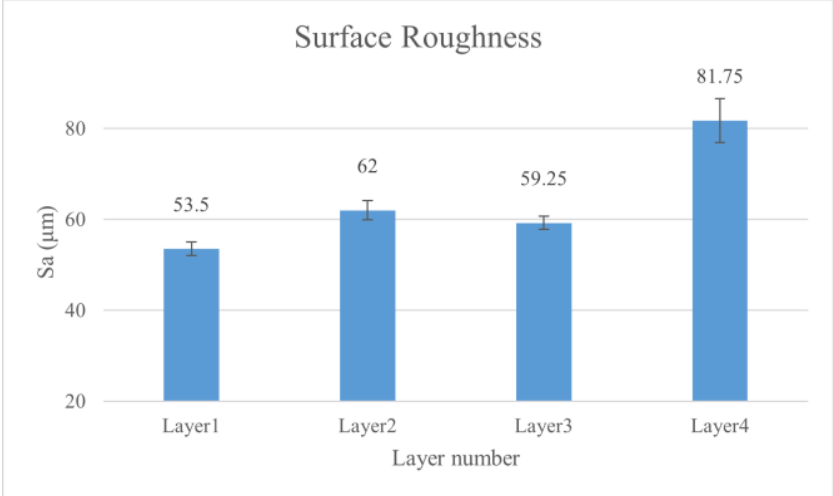

Fig.19 The surface roughness of each layer by DED fabrication sample 2 (unit: $\mu \mathrm{m}$ ) 


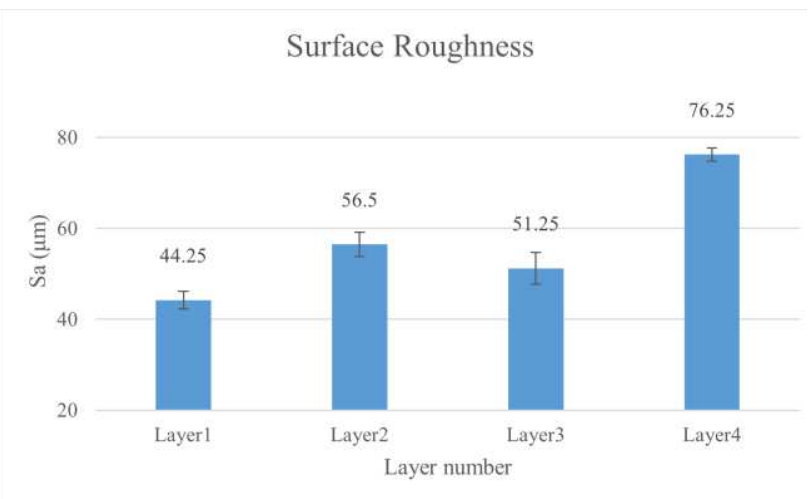

Fig.20 The surface roughness of each layer by DED fabrication sample 3 (unit: $\mu \mathrm{m}$ )

The surface roughness has little variation in the first few layers and reaches a higher value at the end of printing for all three samples. The repeatability of the multi-layer printing process is high according to the visualized data of each layer and values of surface roughness, which has demonstrated the DED repair to be a robust technique in remanufacturing industry.

\subsection{DED repair of used part}

The repair was conducted on used engine head parts. The repair material was $316 \mathrm{~L}$ stainless steel.
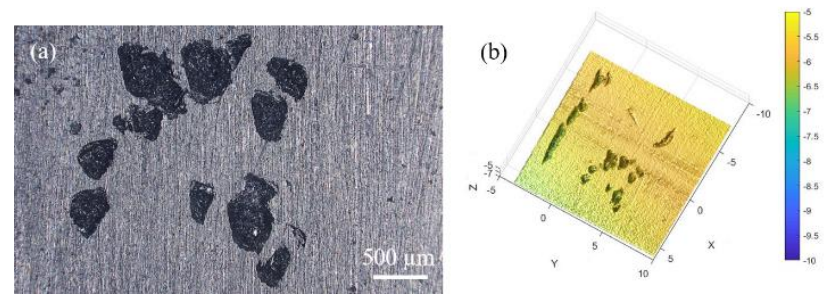

Fig.21 The optical image of engine head sample by a optical microscopy, b SLS scanned data (unit: $\mathrm{mm}$ )

It is easy to locate cracks or dents on the surface of used parts in the manufacturing industry. In this study, optical images of the engine head samples were taken. These defects were distributed unevenly on the substrate. The dimension of these defects was less than $1 \mathrm{~mm}$ on a flat surface. In Figure 21(b), the SLS system was used to capture the object's surface before the repair manufacturing. The model was visualized in Matlab to present the height information for each point on this sample's surface. The established coordinate system was used to track each small defect's location in their point cloud map. The volume of each defect can also be calculated to instruct the subsequent machining process.

The defect sample was prepared for premachining after the SLS system scanned it. The g-code was programmed to remove material by milling. Figure 22 (a) shows that the material in the red square area was removed according to a previous design. A square hole was formed on the surface of the engine head after the milling process was finished. A square pattern that was slightly larger than the square hole was programmed for the DED printing process. There are four layers to ensure that the deposited material is enough to fill the milled hole. The laser power was $500 \mathrm{~W}$, the powder feeding rate is 5 gram/minute, the standoff distance was 5 $\mathrm{mm}$, and the nozzle diameter was $1 \mathrm{~mm}$. The DED deposition of the $316 \mathrm{~L}$ stainless steel material was conducted on the engine head, and SLS scanned, as shown in Figure 22 (b). The repaired area was higher than the surrounding area. Thus the removal of extra material was needed to be performed. The milled part is presented in Figure 22(c). 


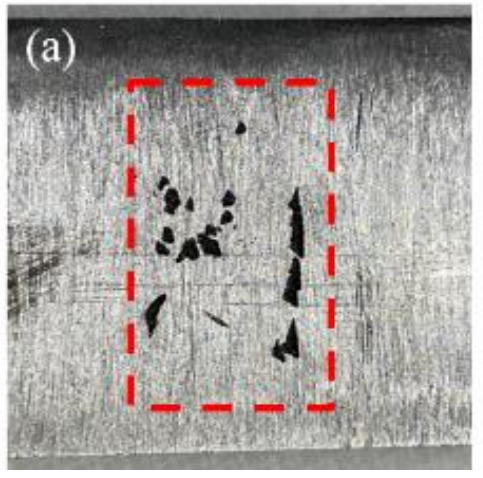

(b)

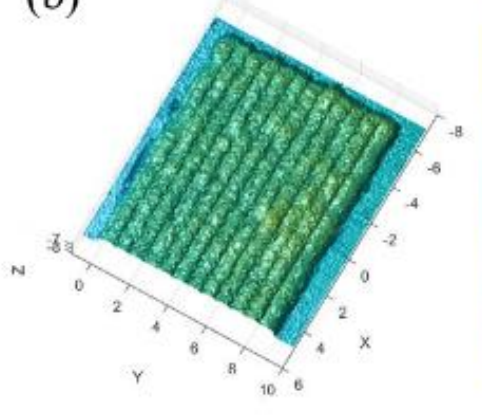

(c)

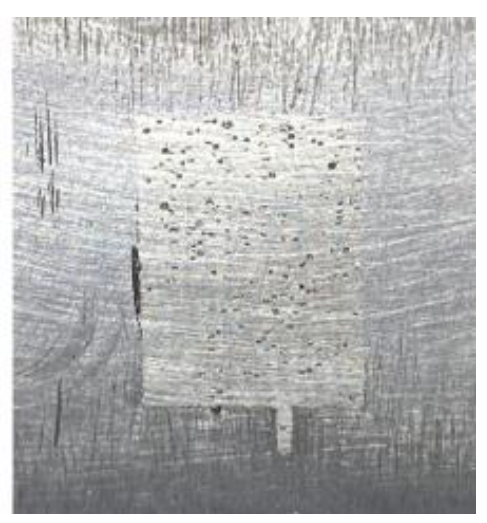

Fig.22 The optical image of the engine head sample by a optical microscopy, b SLS image of the sample (unit: $\mathrm{mm}$ ), $\mathbf{c}$ the milled sample

The defect area was filled with new 316L stainless steel material. Although the deposition material was different from the substrate material, the repair was still accomplished, resulting in good surface roughness of repaired part. There are still some porosities on the surface due to the cast iron substrate's carbon material, which can be further addressed by optimizing printing parameters. This is a common issue on DEDbased repair of cast iron. The deposition of 316L stainless steel to repair defects on the engine head was demonstrated to be effective.

\subsection{CT results}
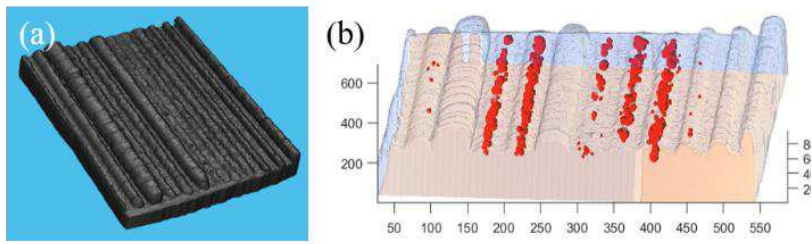

Fig.23 The CT characterization of the multiparameter printed sample by a 3D reconstructed sample, b visualized porosity distribution

The deposited material may have internal cracks or porosity defects. The nondestructive evaluation provides an approach to examine the DED printed part without destroying the manufactured part to detect these defects. CT is one of the most effective nondestructive evaluation approaches to get a high-resolution threedimensional model and a view of the metal sample's interior structure. If the metal sample is too thick, the X-ray would not be able to penetrate the sample. Thus, the extra material on the printed sample was machined, and then the sample was sent to be scanned by CT device.

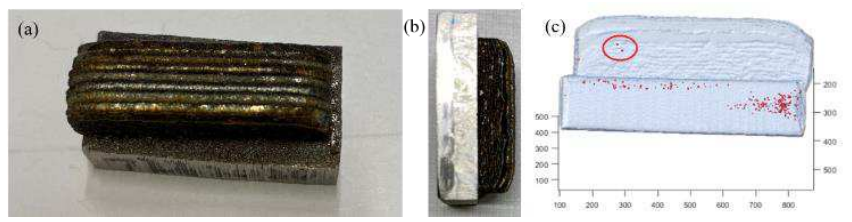

Fig.24 The X-ray characterization of samples printing on stainless steel substrate by a and b different views of printed sample, c porosity distribution of the printed sample

\subsection{Correlation of surfaces from SLS and CT system}

In the RAMRS repair framework, the process starts by determining the dimension of the defect by scanning with the SLS system. However, the SLS system is not capable of directly detecting defects like near-surface 
pores. Thus, the aforementioned methods are applied to inspect and locate the internal pores with the micro-CT system. Use the surface as the pubic reference, and the nearsurface defects can also be labeled in SLS data. This section discusses the correlation based on the surface roughness from two Table 4. Areal surface roughness results

\begin{tabular}{|c|c|c|c|c|c|c|c|}
\hline \multirow{2}{*}{ Sample No. } & \multirow{2}{*}{ Area No. } & \multicolumn{3}{|c|}{$\mathrm{Sa}$} & \multicolumn{3}{|c|}{$\mathrm{Sq}$} \\
\hline & & $\mathrm{CT}$ & SLS & $\%$ Diff. & $\mathrm{CT}$ & SLS & $\%$ Diff. \\
\hline \multirow{4}{*}{ S1 } & 1 & 66.72 & 61.43 & 8.24 & 78.84 & 86.99 & 9.82 \\
\hline & 2 & 68.57 & 65.11 & 5.18 & 80.21 & 86.29 & 7.30 \\
\hline & 3 & 72.38 & 71.02 & 1.89 & 84.56 & 93.35 & 9.89 \\
\hline & 4 & 72.38 & 69.01 & 4.77 & 84.95 & 90.63 & 6.47 \\
\hline \multirow{4}{*}{ S2 } & 1 & 250.13 & 243.57 & 2.66 & 308.80 & 301.90 & 2.26 \\
\hline & 2 & 248.01 & 247.49 & 0.21 & 304.99 & 305.11 & 0.04 \\
\hline & 3 & 234.83 & 241.65 & 2.86 & 291.30 & 297.84 & 2.22 \\
\hline & 4 & 240.57 & 248.63 & 3.29 & 292.06 & 304.20 & 4.07 \\
\hline \multirow{4}{*}{ S3 } & 1 & 90.33 & 86.21 & 4.66 & 127.95 & 125.62 & 1.84 \\
\hline & 2 & 99.47 & 93.51 & 6.18 & 141.19 & 135.93 & 3.80 \\
\hline & 3 & 105.82 & 102.22 & 3.46 & 155.10 & 152.52 & 1.68 \\
\hline & 4 & 109.55 & 102.51 & 6.64 & 166.00 & 157.20 & 5.44 \\
\hline
\end{tabular}

The difference in the area surface roughness percentage of the two sets of data is less than $10 \%$, and the absolute difference is less than the voxel size, which indicates a good correlation considering the characteristics of the DED process. One of the main reasons for the difference between the two is that the SLS system is an optical detection method, and some information will be lost in the valley. Another reason that may cause this is the artifacts from the CT scanning and the segmentation parameters.

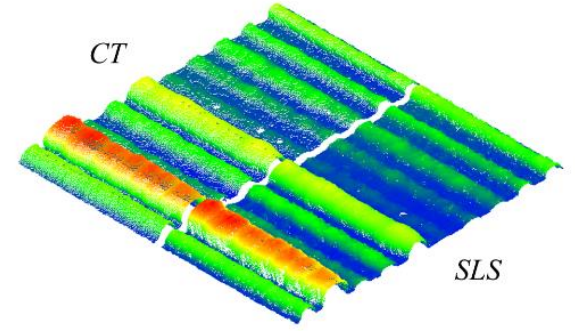

Fig.25 Surface data of Sample 2 from CT and SLS

The two surface datasets (see Fig. 25) are evaluated with point-cloud comparison systems, point-cloud comparison, and Pearson's coefficients.

For each sample, surfaces from four different areas are collected. Then $\mathrm{Sa}$ and $\mathrm{Sq}$ values and the percentage difference of the samples are calculated and listed in Table 4. 
The $\mathrm{Z}$ coordinates from the two data sets were analyzed by Pearson correlation, and the results are shown in Table 6 . The r-values from sample 2 and sample 3 show a strong positive linear correlation, and sample 1 shows a high positive correlation between CT and SLS data (see Fig. 15).

Based on three sets of analysis results, considering the characteristics of DED processing and the CT system's resolution, the surface data from the CT and SLS systems are well matched. Based on this, the surface defects detected by CT can be accurately marked into the SLS system as a reference for further milling defect operations.

Table 6 Pearson correlation coefficient

\begin{tabular}{ccc}
\hline & Pearson's $r$ & $p$-value \\
\hline Sample 1 & 0.8136 & $<0.001$ \\
Sample 2 & 0.9473 & $<0.001$ \\
Sample 3 & 0.9430 & $<0.001$ \\
\hline
\end{tabular}
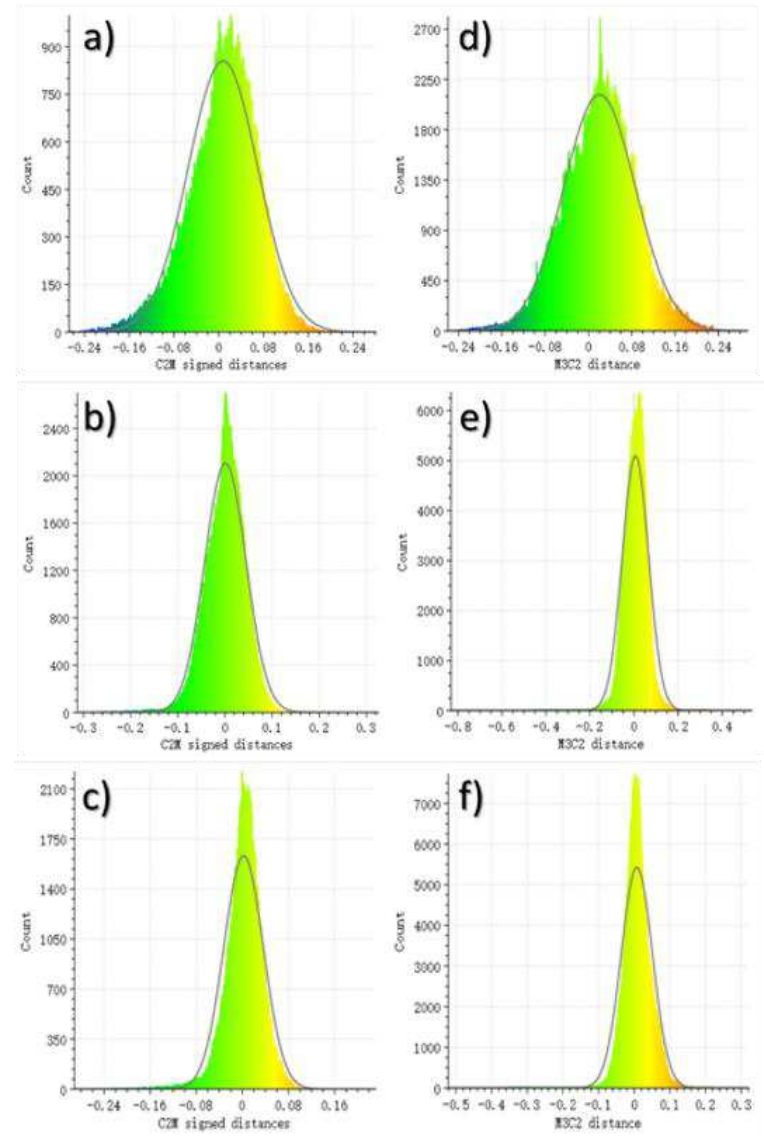

Fig.26 Histograms of the mean distance from $\mathrm{C} 2 \mathrm{M}$ and $\mathrm{M} 3 \mathrm{C} 2$ results, (a-c) the histograms of $\mathrm{C} 2 \mathrm{M}$ results for Sample 1-3, (d-f) the histograms of M3C2 results for Sample 1- 3
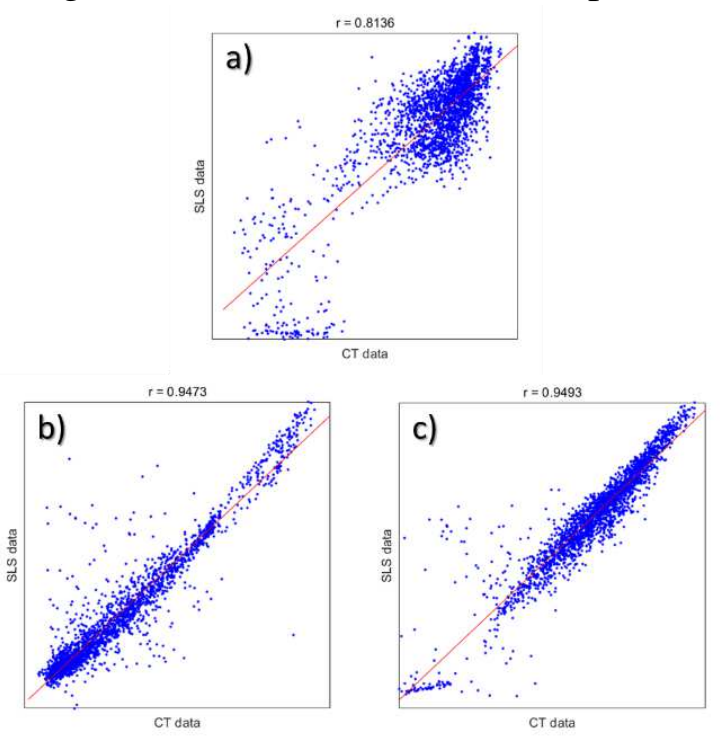

Fig.27 Scatterplot showing the correlation of two kinds of datasets for a Sample 1, b sample 2, c sample3

\section{Conclusion}

In this research, we establish a new system, RAMRS (Real-time AM repair system), to demonstrate the effective repair of the used engine head part with the real-time structured light system's assistance. During the manufacturing process, each printed layer's surface quality could be monitored and calculated by the SLS system to ensure highquality repair. In the end, a nondestructive evaluation method was used to prove the interior quality of the deposited material. The RAMRS has demonstrated a novel method to utilize metal additive manufacturing techniques for repairing used parts. It benefits the manufacturing industry by avoiding the disposal of used parts by high-quality and reliable repair techniques. The main results are as follows: 
- It was found that higher scanning speeds could help to print smaller filaments, and lower scanning speeds shall be selected for the fabrication of large filaments. Different repair strategies were used based on the type of defect.

- The surface point cloud data of a printed four-layer samples were scanned and presented. Each layer has a uniform surface with a variation of height within thirty micrometers.

- The nondestructive approach (CT) was used to analyze the interior quality of the DED printed sample. It was found that the stainless steel substrate could result in much less porosity in comparison with the cast iron substrate. Surface extractions from micro-computed tomography data were conducted to demonstrate the capability of the $\mu$-CT system for surface topography, especially for those irregular surfaces fabricated with metal additive manufacturing, such as direct energy deposition.

- The samples are scanned with both $\mu$ CT and SLS systems, and the SLS data was applied as the reference model. In the surface extraction process from CT data, a combination of CL-Ridler thresholding and locally adaptive segmentation method is applied to achieve a better surface determination performance. Before the comparison, the extracted surfaces from CT data were aligned and rescaled using the SLS data as the reference, then trimmed into the same size at the region of interest. In the end, the paired datasets were evaluated with areal surface roughness, point-cloud comparison, and Pearson correlation coefficient.

- All the percentage difference for areal surface roughness between the two datasets were less than $10 \%$. The average distance between the two sets of surfaces is less than or approximately the voxel size through the test of three point cloud comparison methods. The results of the Pearson correlation coefficient showed strong linear correlations between the CT and SLS data. These results confirm that the $\mathrm{CT}$ system is capable of extracting complex and irregular curved surfaces at a subvoxel level.

In the future, the study will be focused on data fusion of the SLS data and CT data to optimize the RAMRS technique. CT takes hours to obtain the sample's point cloud data, while SLS has the real-time capability to obtain the surface point cloud data. Based on the correlated surface data, more relationship between the internal defects and interlayer information such as surface topography, thermal history, and residual stress can be further correlated. Our future works will focus on multi-sensor data fusion assisted with machine learning techniques for metrology and defects detection and prediction in the AM process. Besides, the repair quality will be studied by designing experiments to address the problem of porosities that occurred on cast iron substrate.

\section{Ethical Approval}

All procedures performed in studies, where applicable, were in accordance with the ethical standards of Iowa State University and/or national research committee and with the 1964 Helsinki declaration and its later amendments or comparable ethical standards. 


\section{Consent to Participate}

Informed consent was obtained from all individual participants included in the study.

\section{Consent to Publish}

The participant has consented to the submission of the research to the journal.

\section{Authors Contributions}

Conceptualization, X.Z., I.R., B.L, and H.Q.; methodology, X.Z., W.S., V.S., J. H., L-H.Y., X.J., Z.Z., X.J., and H.Q.; software, X.Z., W.S., V.S., J. H., L-H.Y., X.J.; validation, X.Z., W.S., V.S., J. H., L-H.Y., X.J., and X.J.; formal analysis, X.Z., W.S., V.S., J. H., L-H.Y., X.J., and X.J.; investigation, X.Z., W.S., V.S., J. H., L-H.Y., X.J., and X.J.; resources, X.Z., W.S., V.S., J. H., L-H.Y., X.J.; data curation, X.Z., W.S., V.S., J. H., L-H.Y., X.J.; writing-original draft preparation, X.Z., W.S., X.J.; writingreview and editing, X.J., Y.C., Z.Z., and H.Q.; visualization, X.Z.; supervision, H.Q.; project administration, H.Q.; funding acquisition, I.R., B.L., H.Q. All authors have read and agreed to the published version of the manuscript.

\section{Funding}

This paper is based upon work supported by the U.S. Department of Energy's Office of Energy Efficiency and Renewable Energy (EERE) under the Advanced Manufacturing Office Award Number DE-EE0007897, and by Exploratory Research Project grant from Department of Industrial and Manufacturing Systems Engineering (IMSE_ERP) at Iowa State University. Their supports are greatly appreciated.

\section{Competing Interests}

This report was prepared as an account of work sponsored by an agency of the United States Government. Neither the United States Government nor any agency thereof, nor any of their employees, makes any warranty, express or implied, or assumes any legal liability or responsibility for the accuracy, completeness, or usefulness of any information, apparatus, product, or process disclosed, or represents that its use would not infringe privately owned rights. Reference herein to any specific commercial product, process, or service by trade name, trademark, manufacturer, or otherwise does not necessarily constitute or imply its endorsement, recommendation, or favoring by the United States Government or any agency thereof. The views and opinions of authors expressed herein do not necessarily state or reflect those of the United States Government or any agency thereof.

\section{Availability of data and materials}

The authors confirm that the data supporting the findings of this study are available within the article.

\section{References}

1. Vartanian K, McDonald T (2016) Accelerating industrial adoption of metal additive manufacturing technology. Jom 68(3):806-810

2. Ahn DG (2016) Direct metal additive manufacturing processes and their sustainable applications for green technology: A review. International Journal of Precision Engineering and Manufacturing-Green Technology 3(4):381-395

3. Wilson JM, Piya C, Shin YC, Zhao F, Ramani K (2014) Remanufacturing of turbine blades by laser direct deposition with its energy and environmental impact analysis. Journal of Cleaner Production 80:170-178

4. Graf B, Gumenyuk A, Rethmeier M (2012) Laser metal deposition as repair technology for stainless steel and titanium alloys. Physics Procedia 39:376-381 
5. Leunda J, Soriano C, Sanz C, Navas VG (2011) Laser cladding of vanadium-carbide tool steels for die repair. Physics Procedia 12:345-352

6. Onuike B, Bandyopadhyay A (2019) Additive manufacturing in repair: Influence of processing parameters on properties of Inconel 718. Materials Letters 252:256-259

7. Shuai C, Cheng Y, Yang Y, Peng S, Yang W, Qi F (2019) Laser additive manufacturing of Zn-2Al part for bone repair: Formability, microstructure and properties. Journal of Alloys and Compounds 798:606-615

8. Petrat T, Brunner-Schwer C, Graf B, Rethmeier M (2019) Microstructure of Inconel 718 parts with constant mass energy input manufactured with direct energy deposition. Procedia Manufacturing 36:256266

9. Wang Z, Palmer TA, Beese AM (2016) Effect of processing parameters on microstructure and tensile properties of austenitic stainless steel 304L made by directed energy deposition additive manufacturing. Acta Materialia 110:226-235

10. Feenstra DR, Cruz V, Gao X, Molotnikov A, Birbilis N (2020) Effect of Build Height on the Properties of Large Format Stainless Steel 316L Fabricated via Directed Energy Deposition. Additive Manufacturing 25:101205

11. Woo W, Kim DK, Kingston EJ, Luzin V, Salvemini F, Hill MR (2019) Effect of interlayers and scanning strategies on through-thickness residual stress distributions in additive manufactured ferriticaustenitic steel structure. Materials Science and Engineering: A 744: 618-629

12. Shim DS, Baek GY, Lee EM (2017) Effect of substrate preheating by induction heater on direct energy deposition of AISI M4 powder. Materials Science and Engineering: A 682:550-562

13. Chua ZY, Ahn IH, Moon SK (2017) Process monitoring and inspection systems in metal additive manufacturing: Status and applications. International Journal of Precision Engineering and ManufacturingGreen Technology 4(2):235-245

14. Elliot AM, Love LJ (2016) Operator burden in metal additive manufacturing. Solid Freeform Fabrication 1:1890-1899

15. Hofman JT, Pathiraj B, Van Dijk J, De Lange DF, Meijer J (2012) A camera based feedback control strategy for the laser cladding process. Journal of Materials Processing Technology 212(11):2455-2462 16. Craeghs T, Clijsters S, Yasa E, Bechmann F, Berumen S, Kruth JP (2011) Determination of geometrical factors in Layerwise Laser Melting using optical process monitoring. Optics and Lasers in Engineering 49(12):1440-1446

17. Farshidianfar MH, Khajepour A, Gerlich AP (2016) Effect of real-time cooling rate on microstructure in laser additive manufacturing. Journal of Materials Processing Technology 231:468478

18. Bandyopadhyay A, Traxel KD (2018) Invited review article: Metal-additive manufacturingModeling strategies for application-optimized designs. Additive manufacturing 22:758-774

19. Yang Q, Zhang P, Cheng L, Min Z, Chyu M, To AC (2016) Finite element modeling and validation of thermomechanical behavior of Ti-6Al-4V in directed energy deposition additive manufacturing. Additive Manufacturing 12: 169-177

20. Ding Y, Warton J, Kovacevic R (2016) Development of sensing and control system for robotized laser-based direct metal addition system. Additive Manufacturing 10:24-35

21. Lott $P$, Schleifenbaum H, Meiners W, Wissenbach K, Hinke C, Bültmann J (2011) Design of an optical system for the in situ process monitoring of selective laser melting (SLM). Physics Procedia 12:683-690

22. Li B, Zhang S (2014) Structured light system calibration method with optimal fringe angle. Applied optics 53(33):7942-7950

23. Townsend A, Senin N, Blunt L, Leach RK, Taylor JS (2016) Surface texture metrology for metal additive manufacturing: a review. Precision Engineering 46:34-47

24. Zhang X, Zheng Y, Suresh V, Wang S, Li Q, Li B, Qin H (2020) Correlation approach for quality assurance of additive manufactured parts based on optical metrology. Journal of Manufacturing Processes 53:310-317

25. Zheng Y, Zhang X, Wang S, Li Q, Qin H, Li B (2020) Similarity evaluation of topography measurement results by different optical metrology technologies for additive manufactured parts. Optics and Lasers in Engineering 126:105920

26. Suresh V, Zheng Y, Zhang X, Wang S, Qin H, Li Q, Li B (2020) Similarity evaluation of 3D topological measurement results using statistical methods. In Dimensional Optical Metrology and Inspection for Practical Applications IX 11397: 113970A

27. Melugiri-Shankaramurthy B, Sargam Y, Zhang X, Sun W, Wang K, Qin H (2019) Evaluation of cement paste containing recycled stainless steel powder for sustainable additive manufacturing. Construction and Building Materials 227:116696 
28. Ahn DG (2016) Direct metal additive manufacturing processes and their sustainable applications for green technology: A review. International Journal of Precision Engineering and Manufacturing-Green Technology 3(4):381-395

29. Polamaplly P, Cheng Y, Shi X, Manikandan K, Zhang X, Kremer GE, Qin H (2019) 3D printing and characterization of hydroxypropyl methylcellulose and methylcellulose for biodegradable support structures. Polymer 173:119-126

30. Aggarangsi P, Beuth JL (2006) Localized preheating approaches for reducing residual stress in additive manufacturing. International Solid Freeform Fabrication Symposium

31. Matthews M, Trapp J, Guss G, Rubenchik A (2018) Direct measurements of laser absorptivity during metal melt pool formation associated with powder bed fusion additive manufacturing processes. Journal of Laser Applications 30(3):032302

32. Li B, Zhang S (2015) Flexible calibration method for microscopic structured light system using telecentric lens. Optics express 23(20): 25795-25803 


\section{Figures}
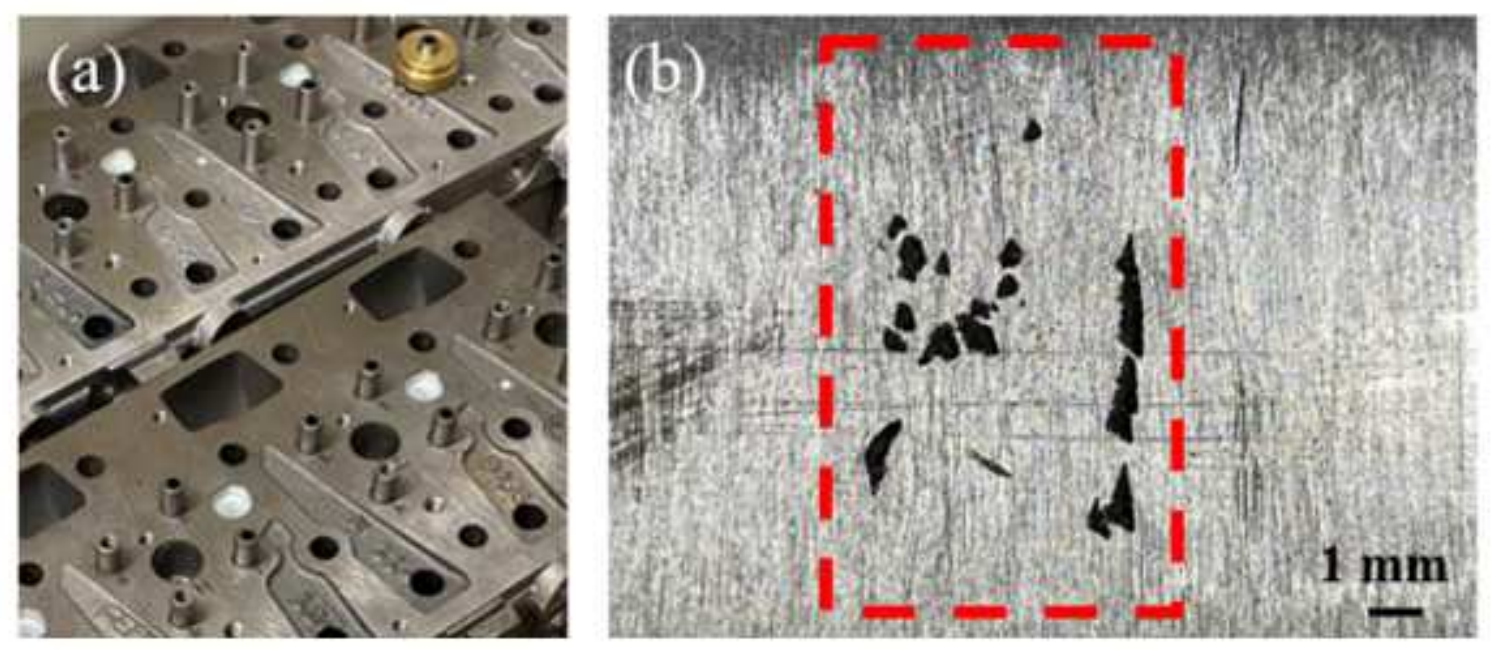

Figure 1

a engine head parts, $b$ sliced engine head with defects on top

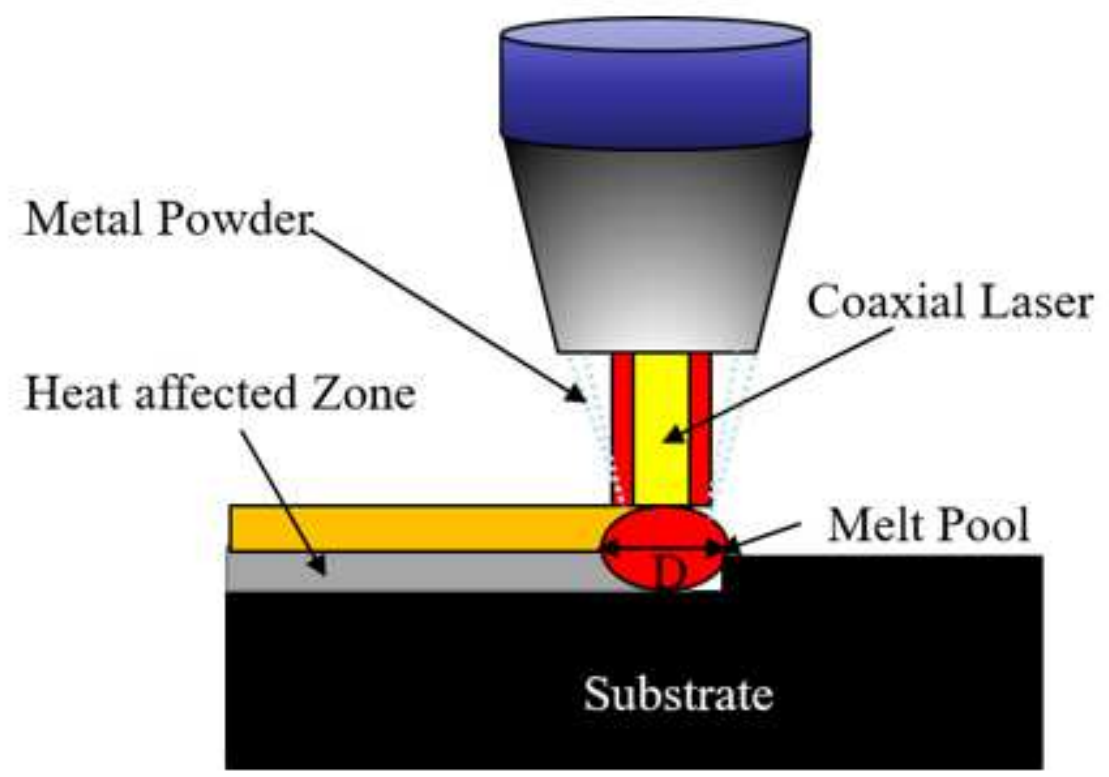

Figure 2

A schematic diagram of the DED process 
(a)

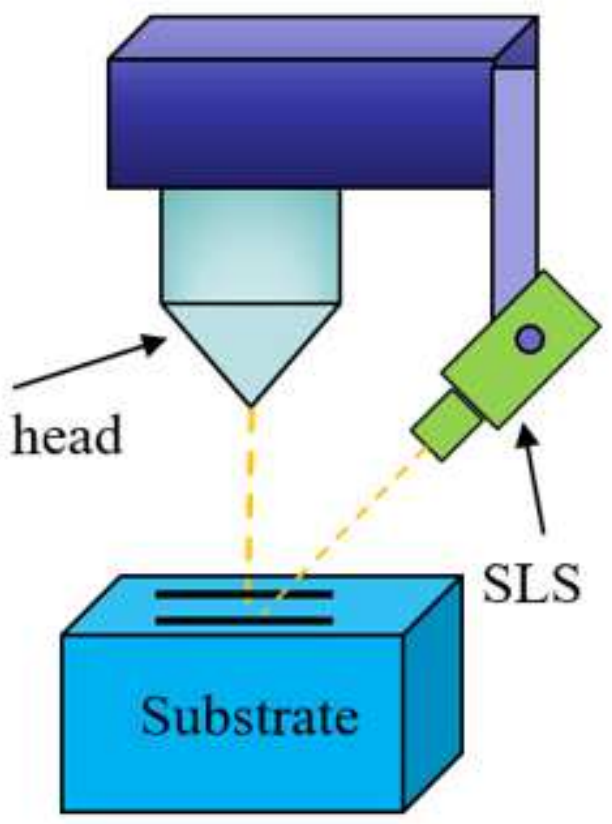

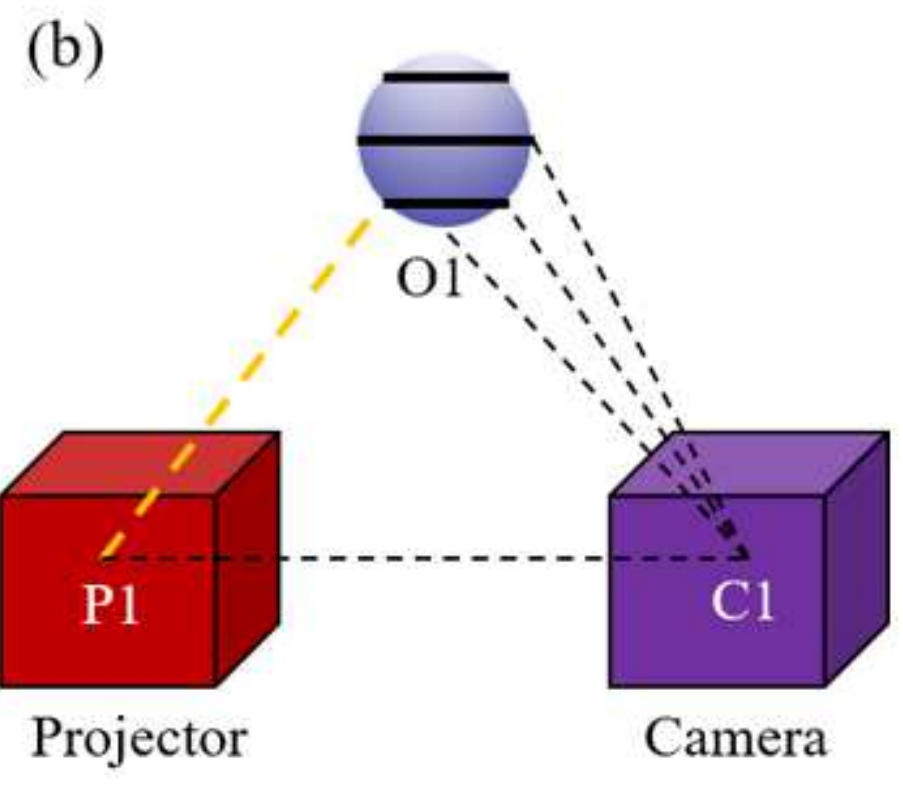

Figure 3

a Setup, $b$ mechanism of the SLS system

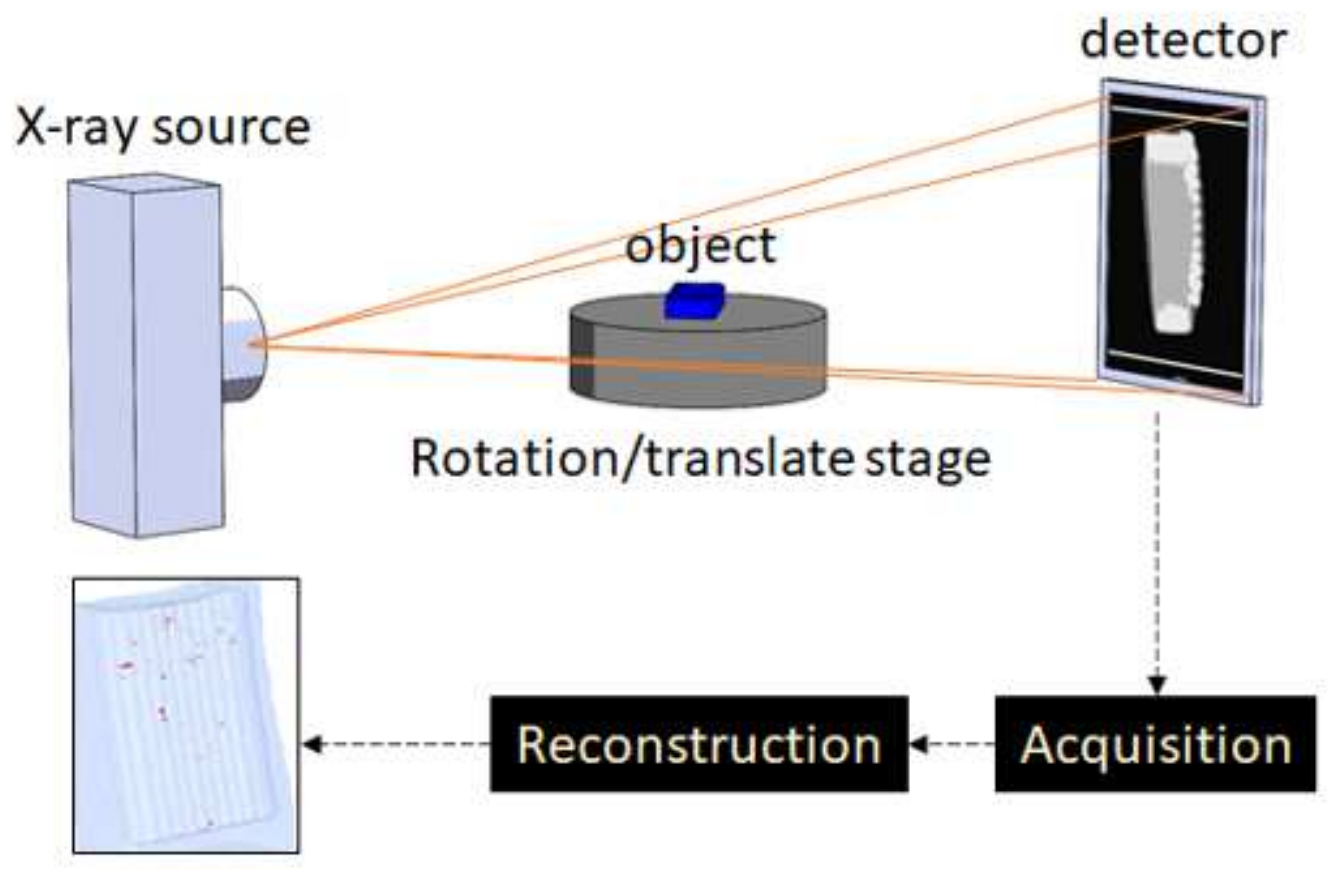

Figure 4

Schematic of the CT system 


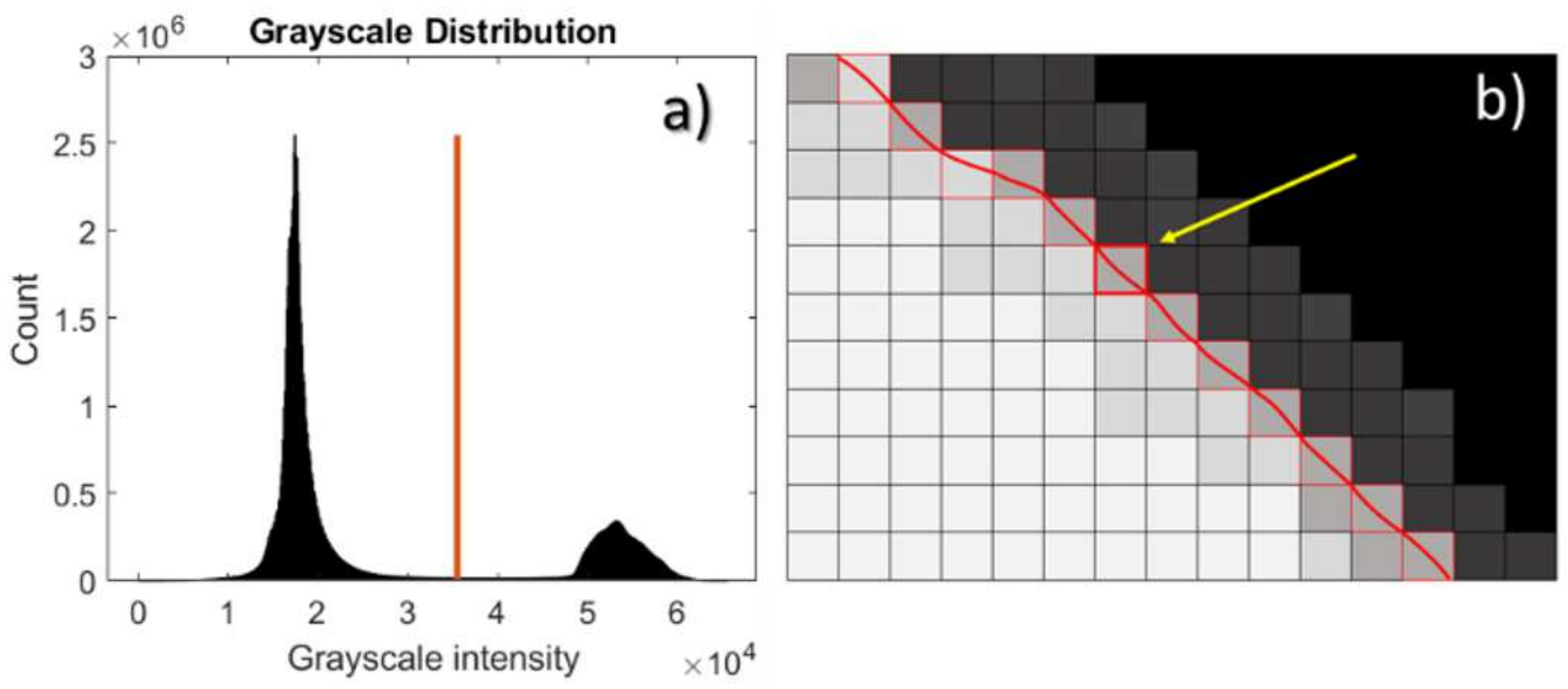

Figure 5

Simplified representation of two segmentation methods a global thresholding based on the grayscale histogram, b locally adaptive method test each pixel with its neighbours
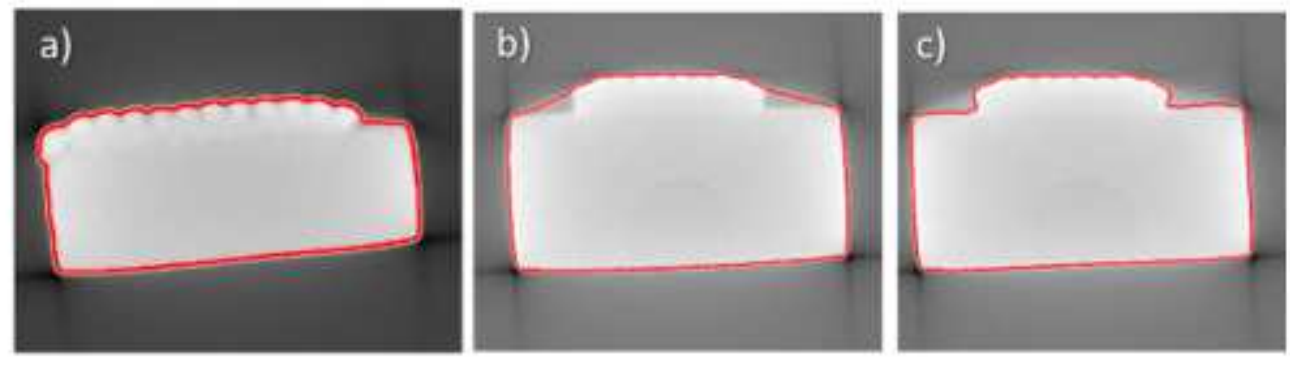

Figure 6

CT slice images processed with different methods, a global thresholding, b a CT slice with scatter artifacts processed with global thresholding, c slice with scatter artifacts processed with locally adaptive segmentation 


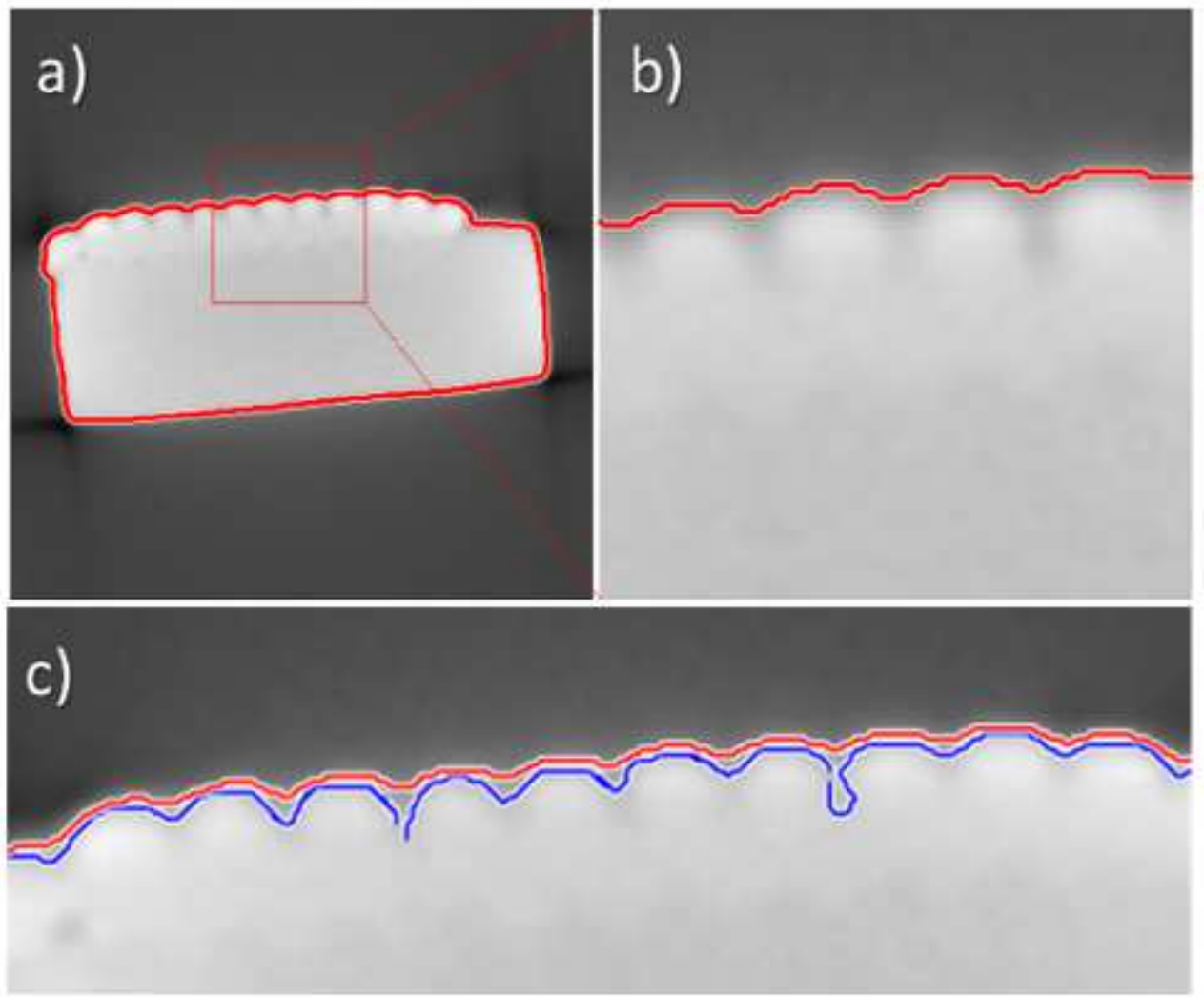

Figure 7

Segmentation of surface from CT data, a applied with locally adaptive segmentation, b zoom-in figure of Fig. 8a, c segmentation comparison between the locally adaptive method (red contour) and the proposed approach (blue contour)

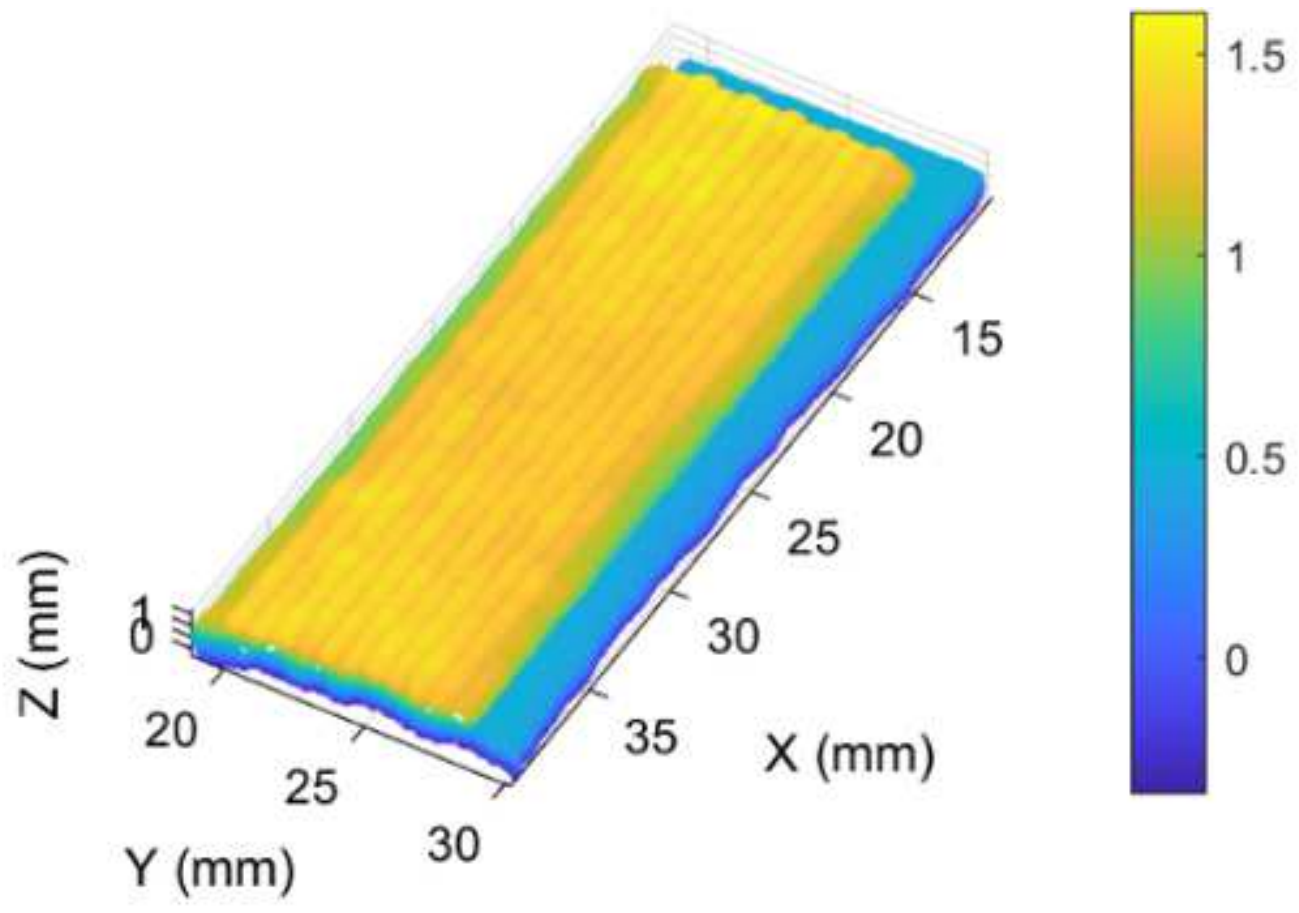

Figure 8 


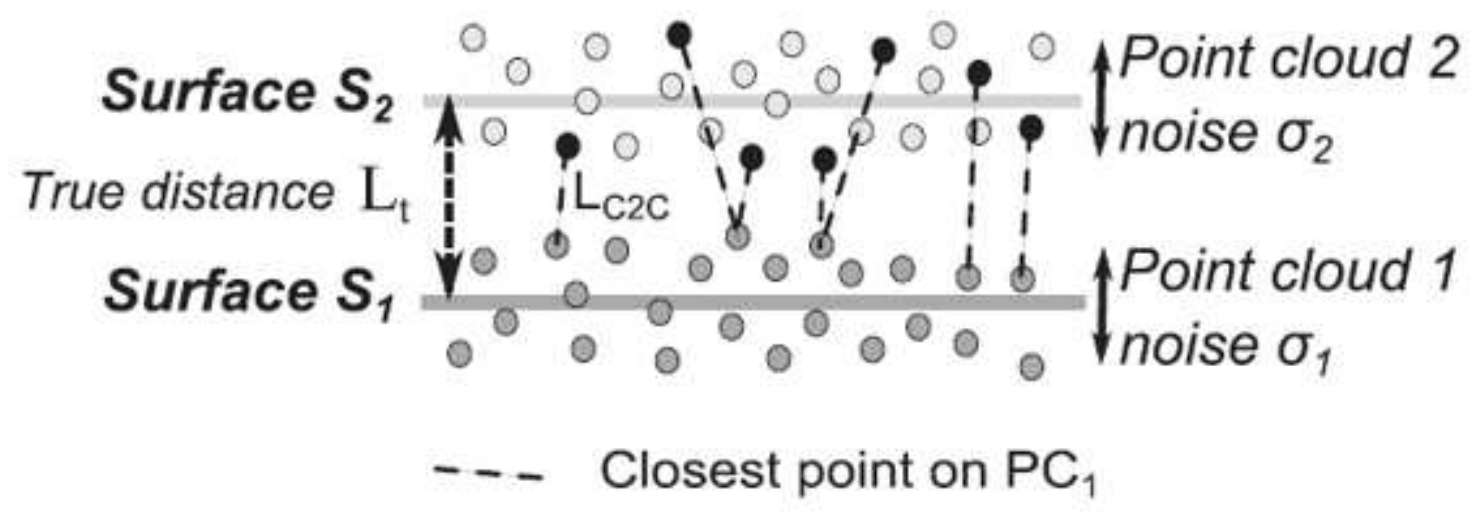

Figure 9

Schematic of C2C method [21]

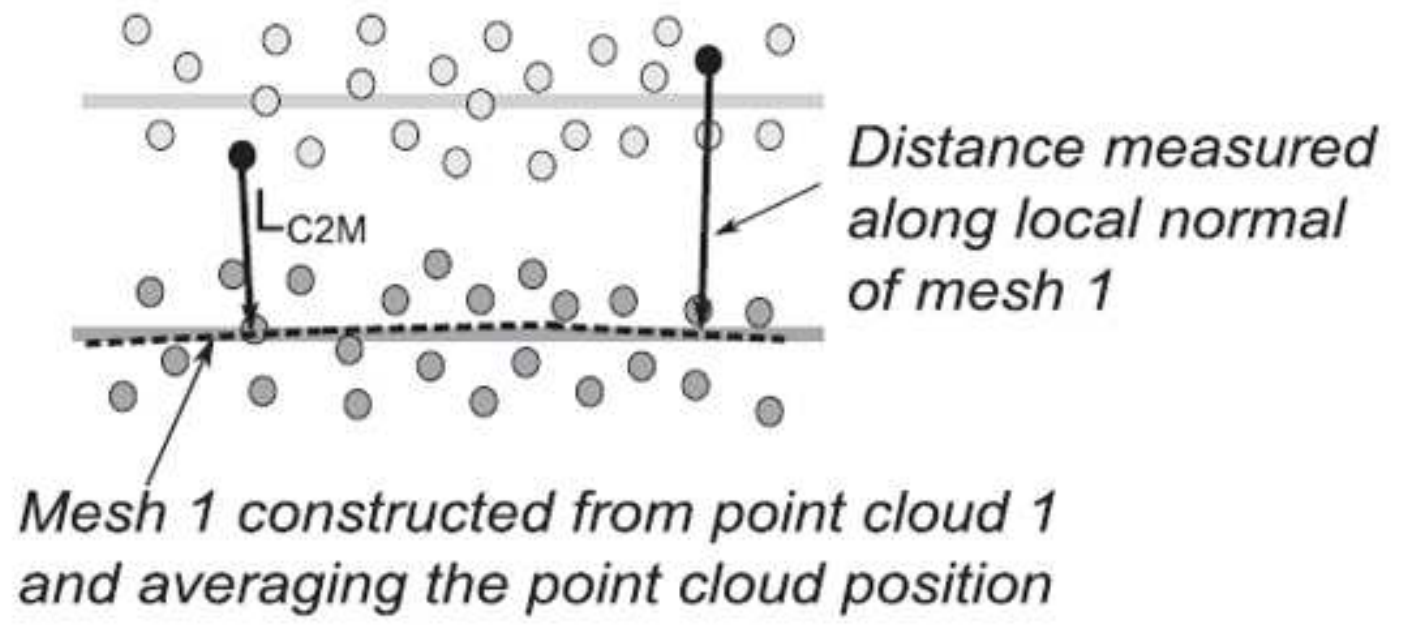

Figure 10

Schematic of C2M method [21] 
Step 1 : Calculation of normal $\vec{N}$ at a scale $D$ around the core point $i$.

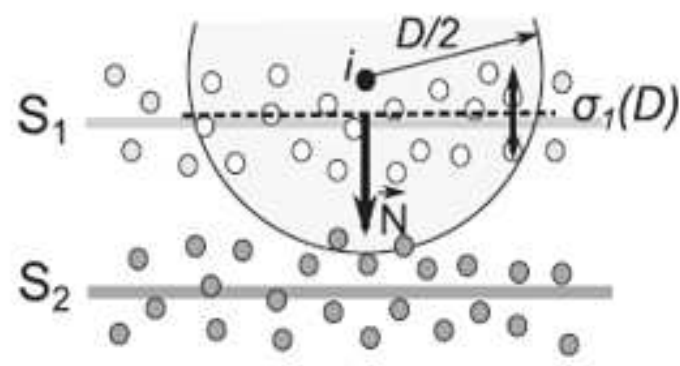

Step 2 : Average distance between the two clouds measured at a scale $d$ along $\hat{\mathrm{N}}$

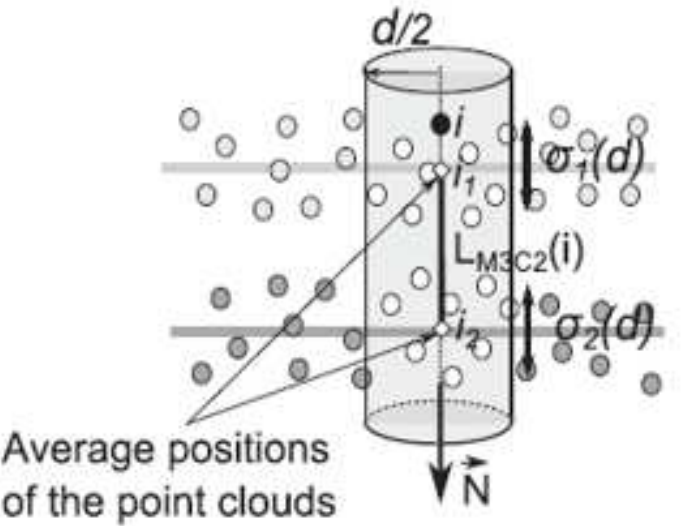

Figure 11

Schematic of M3C2 method [21]

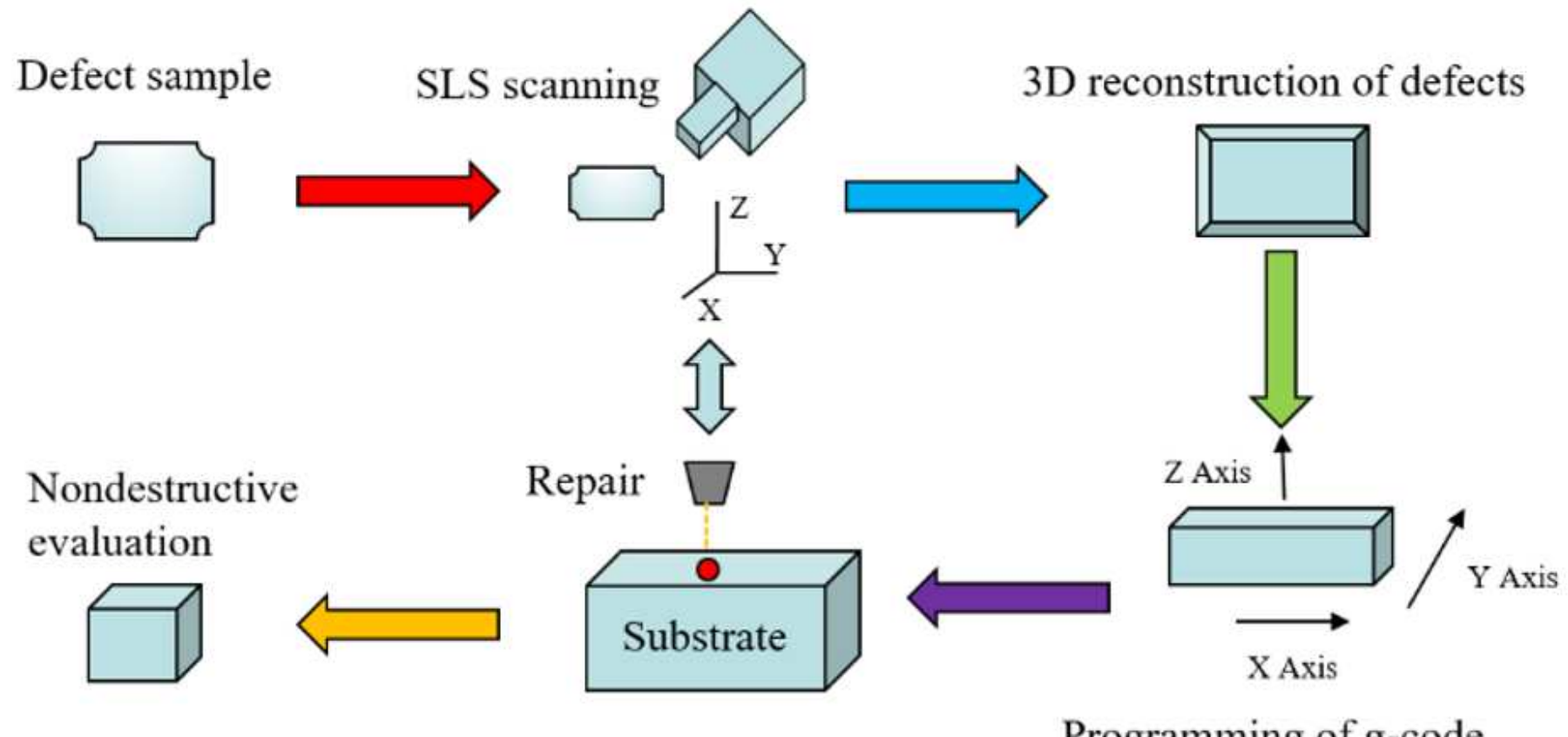

Programming of g-code

Figure 12

Repair framework of used parts 

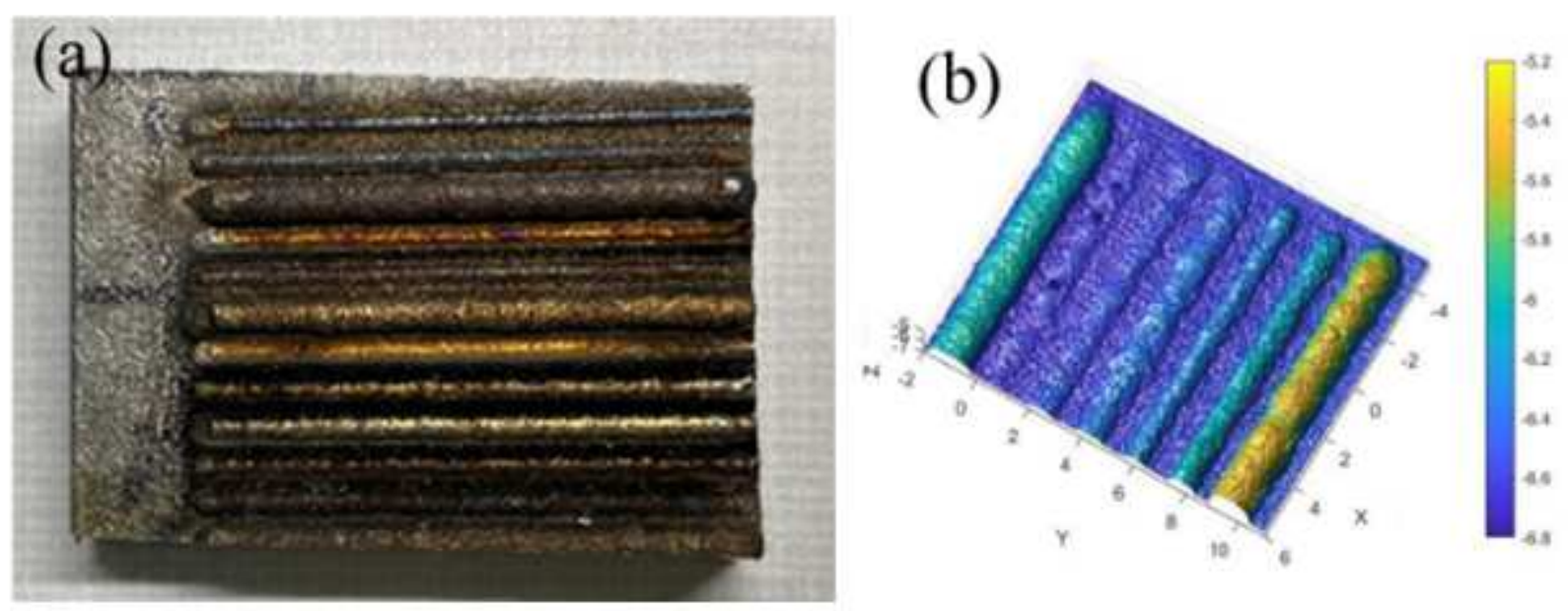

\section{Figure 13}

a A 3D printed sample with different scanning speed, powder feeding rate, and laser power, b scanned sample (unit: $\mathrm{mm}$ )

\section{Influence of printing parameter}

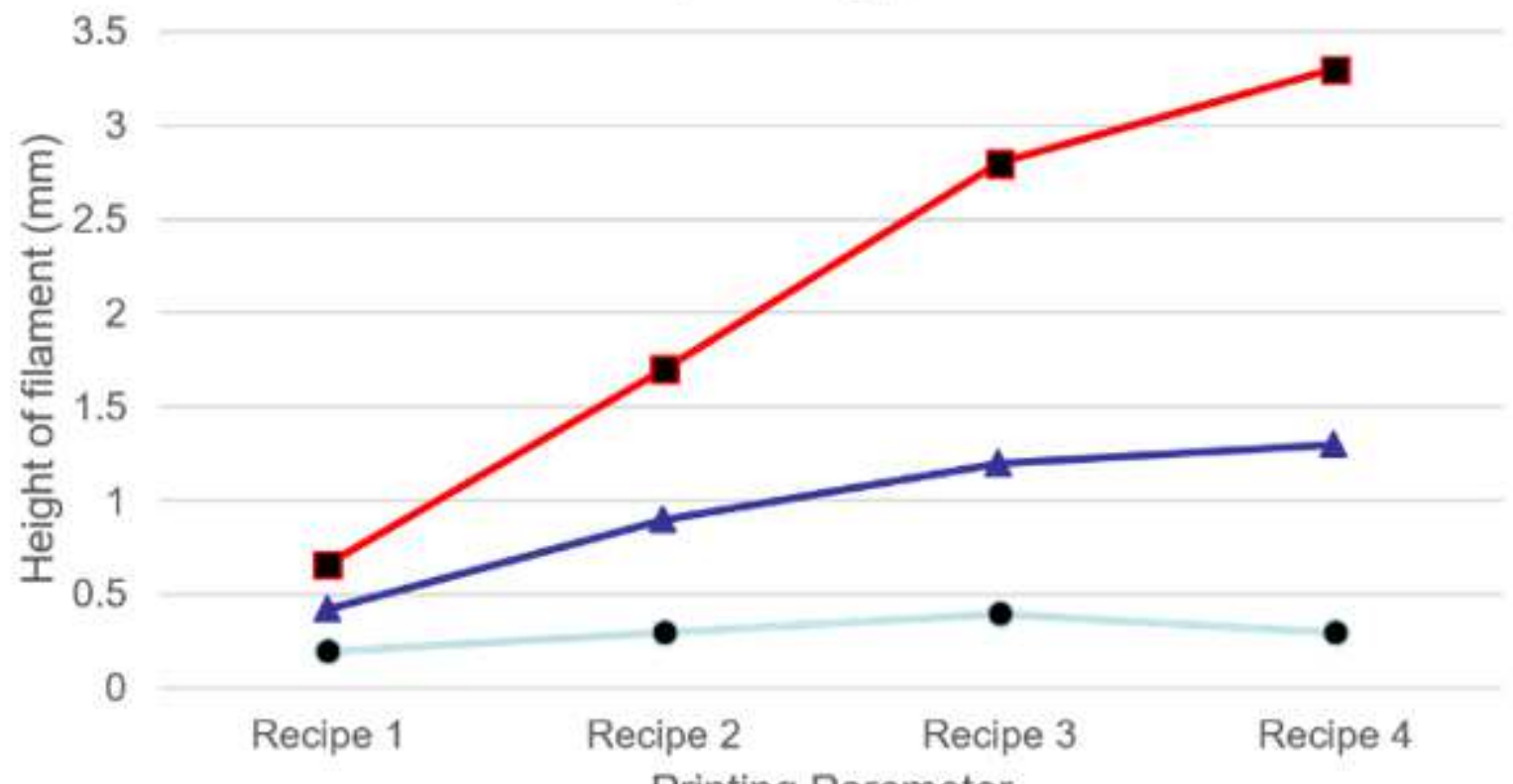

Printing Parameter

- Plotting speed $1 \quad$-Plotting speed $2 \rightarrow$-Plotting speed 3

\section{Figure 14}

DED printed filaments with different treatment combinations of scanning speed and powder feeding rate 

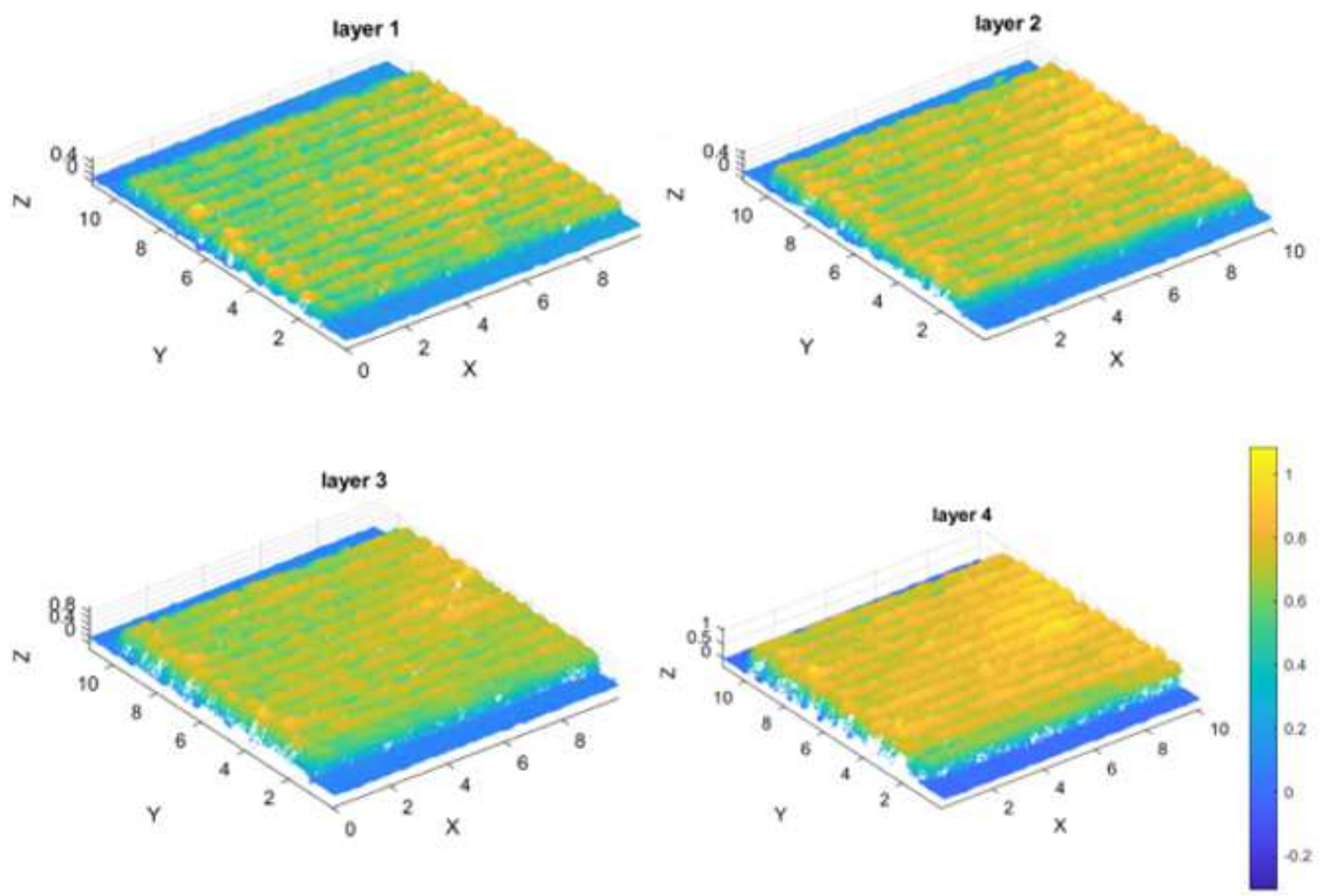

Figure 15

SLS images of each layer of the DED printed sample1 (unit: $\mathrm{mm}$ ) 

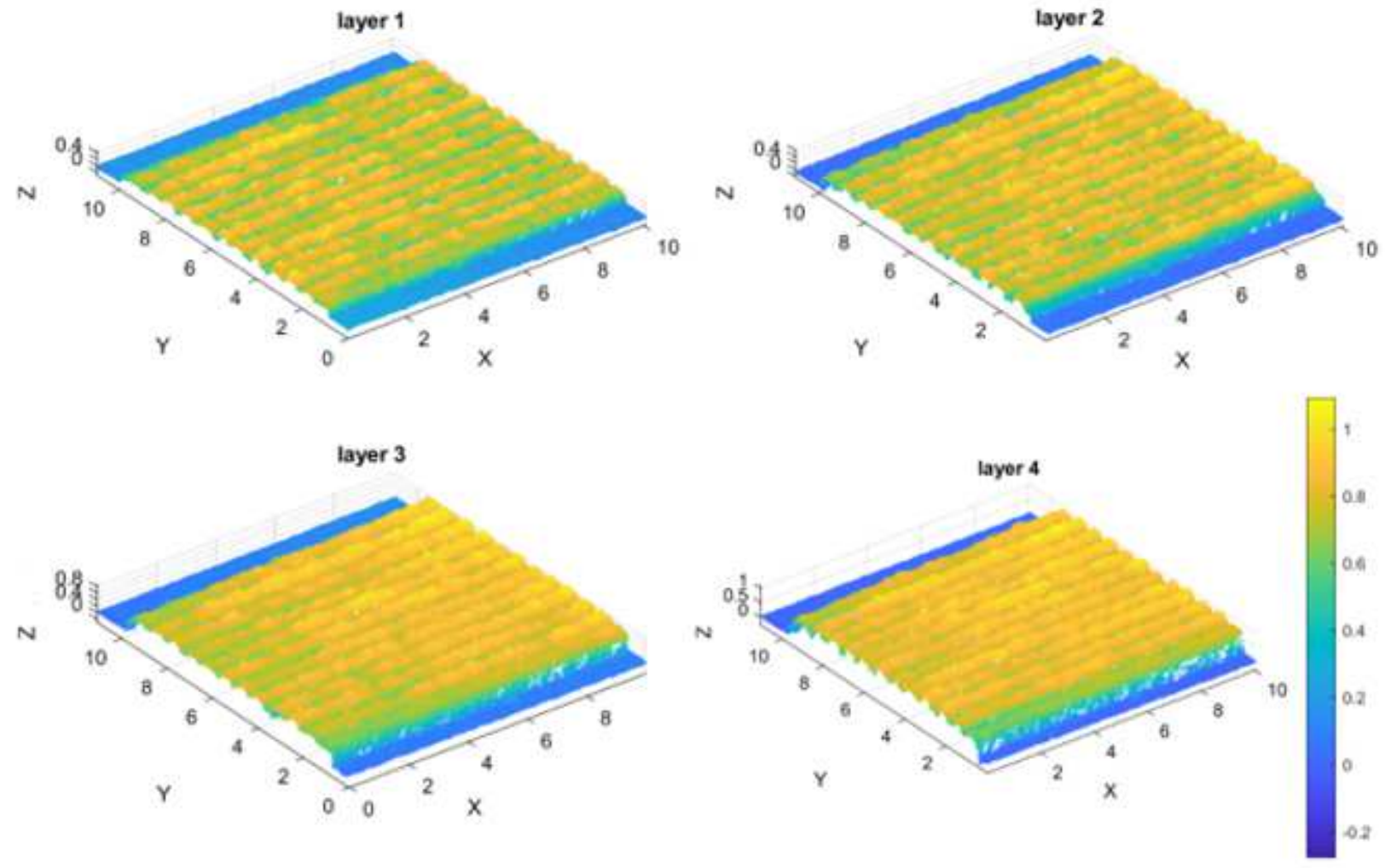

Figure 16

SLS images of each layer of the DED printed sample 2 (unit: $\mathrm{mm}$ )
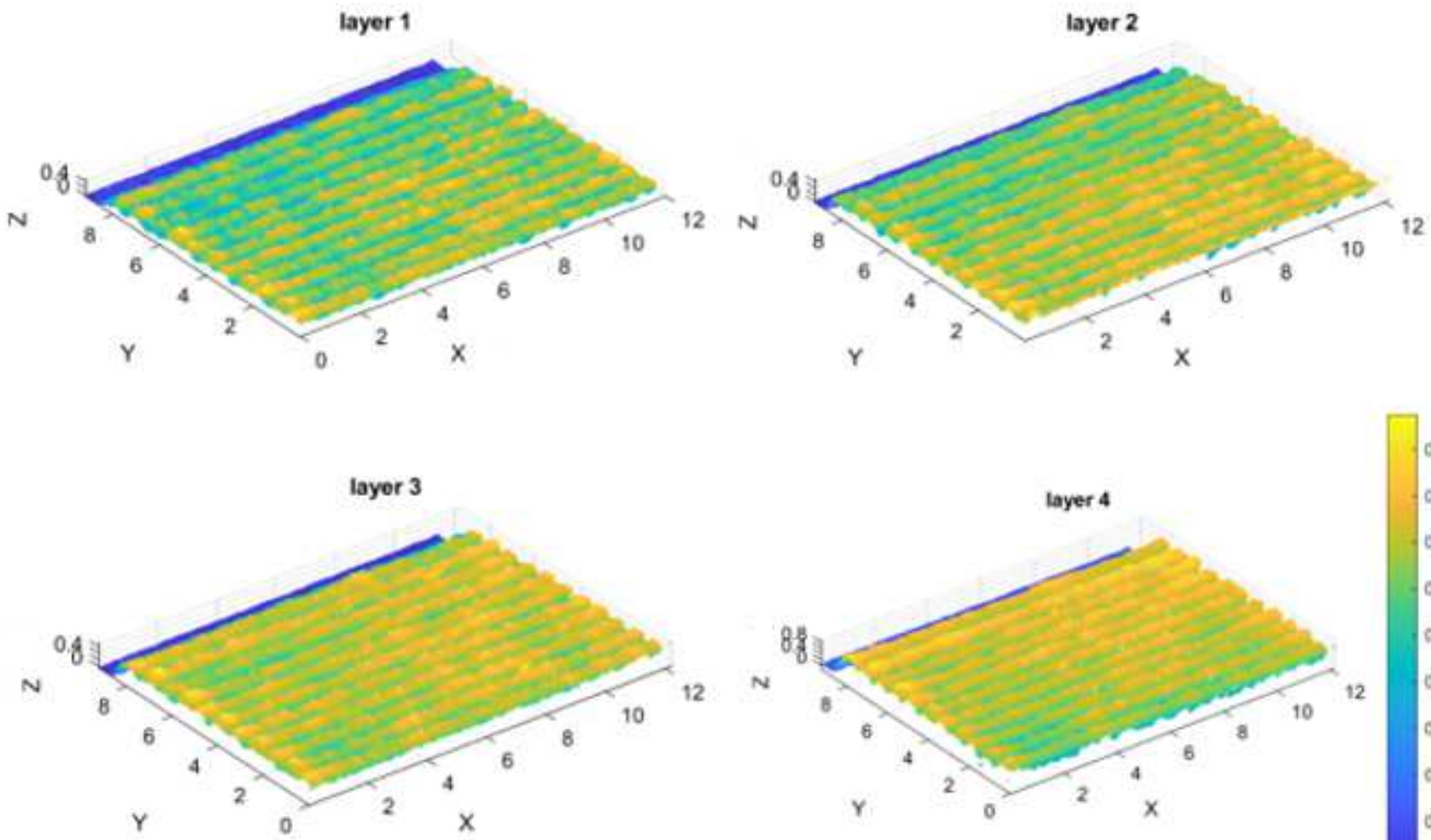
Figure 17

SLS images of each layer of the DED printed sample 3 (unit: $\mathrm{mm}$ )

\section{Surface Roughness}

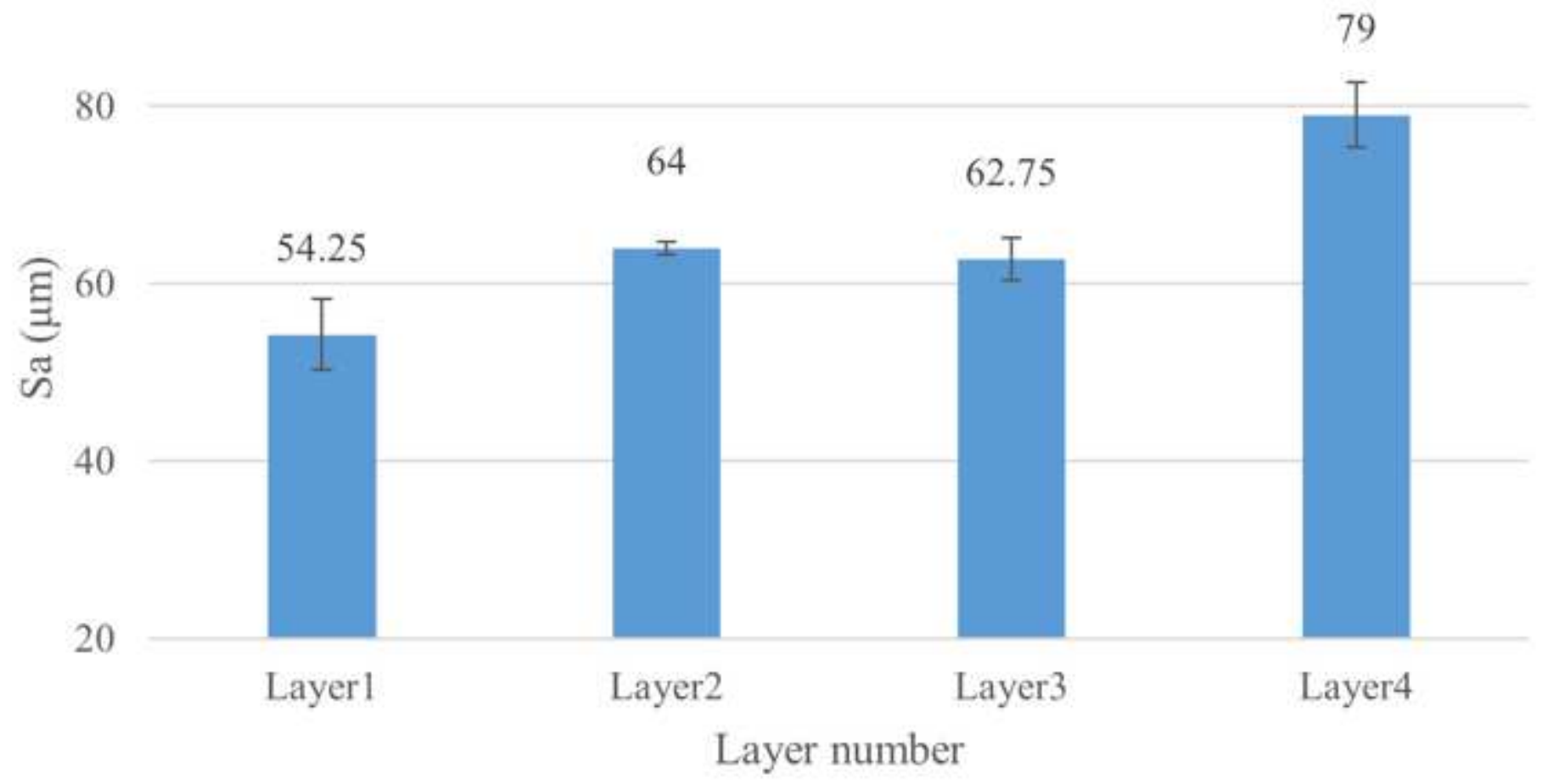

Figure 18

The surface roughness of each layer by DED fabrication sample 1 (unit: $\mu \mathrm{m}$ ) 


\section{Surface Roughness}

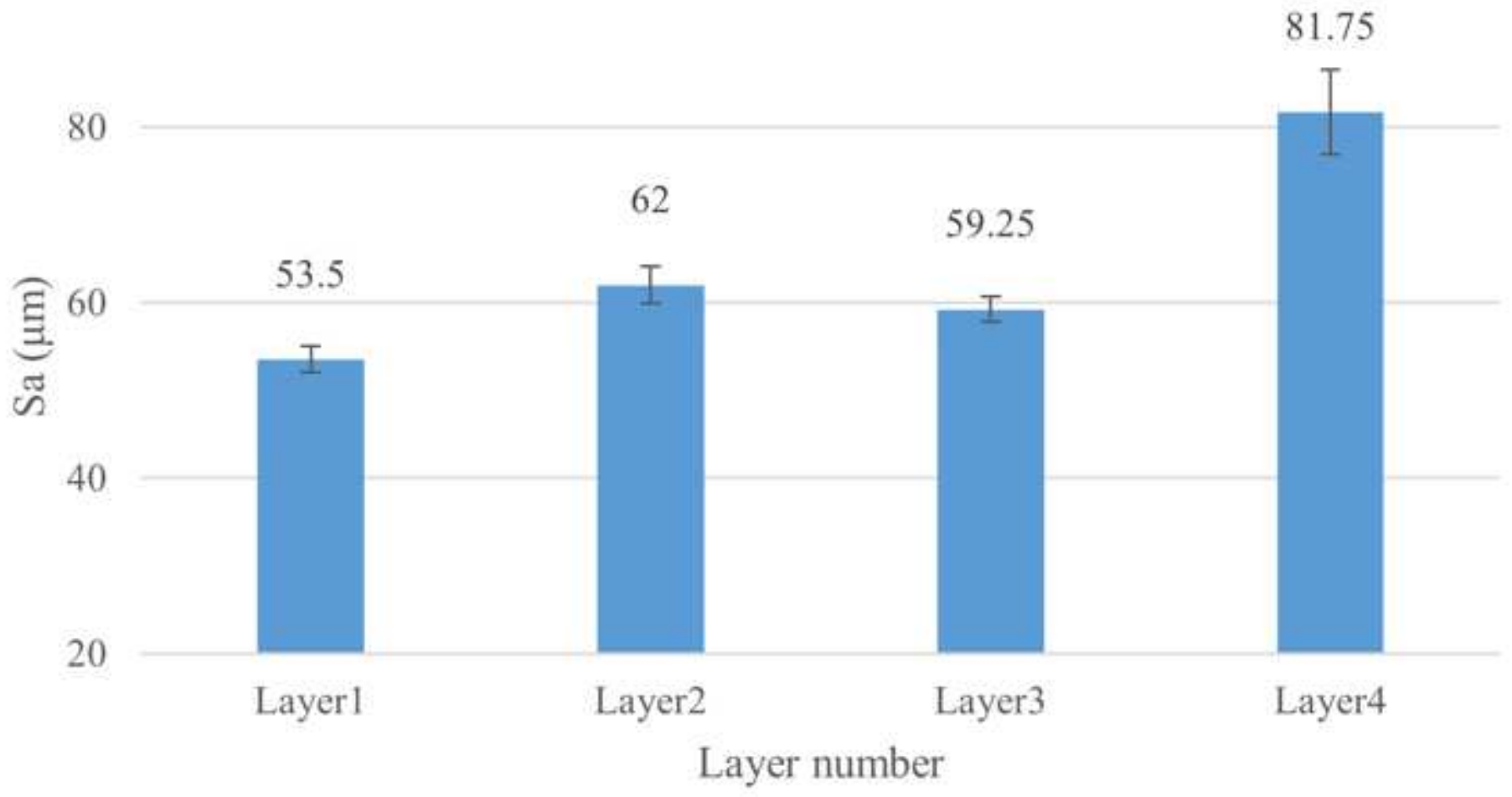

Figure 19

The surface roughness of each layer by DED fabrication sample 2 (unit: $\mu \mathrm{m}$ )

\section{Surface Roughness}

76.25

80

56.5

$\underbrace{\Xi}_{\text {Ð }} 60$

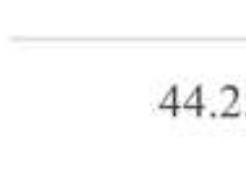

40

20

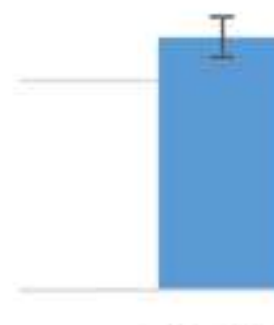

Layer 1
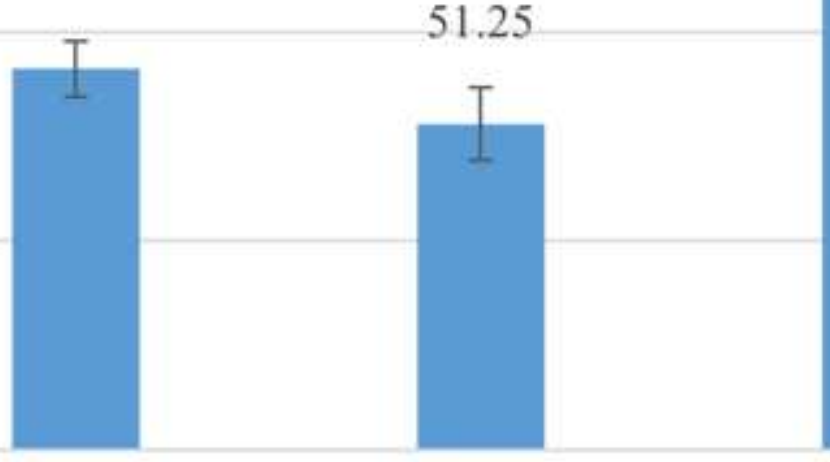

Layer2

Layer3

Layer4

Layer number 
Figure 20

The surface roughness of each layer by DED fabrication sample 3 (unit: $\mu \mathrm{m}$ )
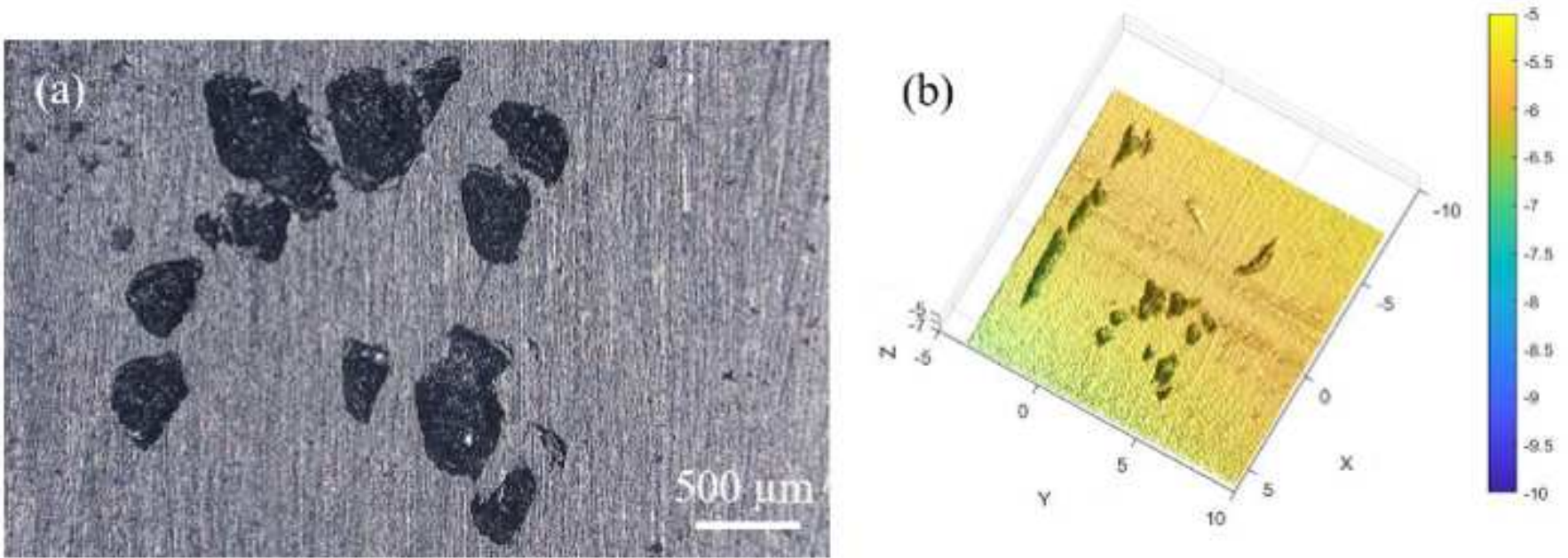

\section{Figure 21}

The optical image of engine head sample by a optical microscopy, b SLS scanned data (unit: mm)

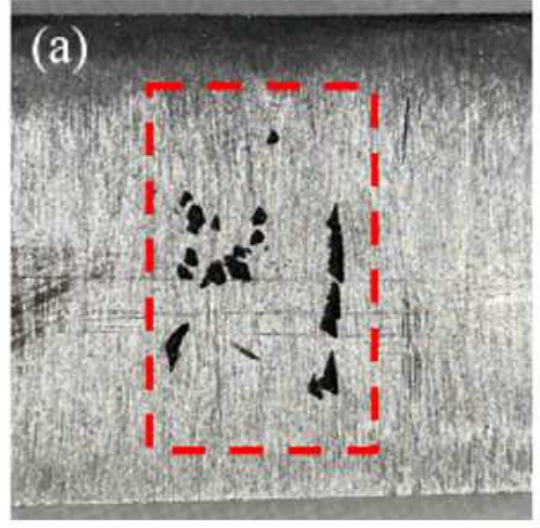

(b)

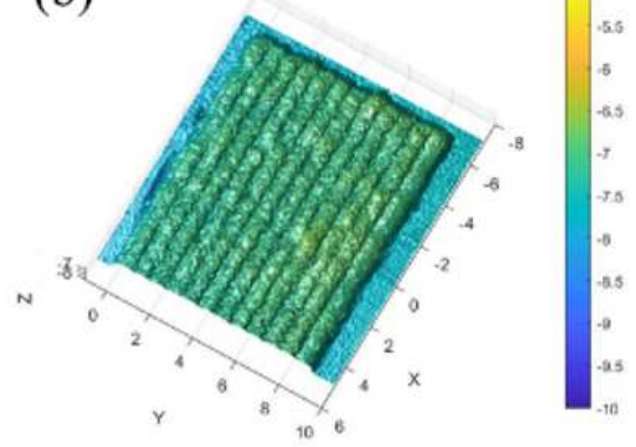

(c)

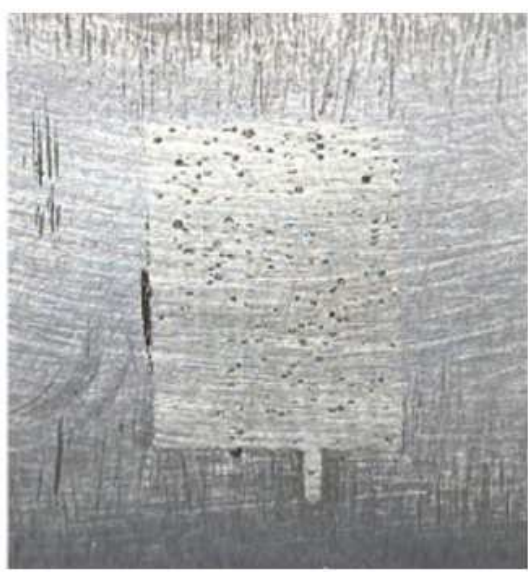

\section{Figure 22}

The optical image of the engine head sample by a optical microscopy, b SLS image of the sample (unit: $\mathrm{mm}), \mathrm{c}$ the milled sample 

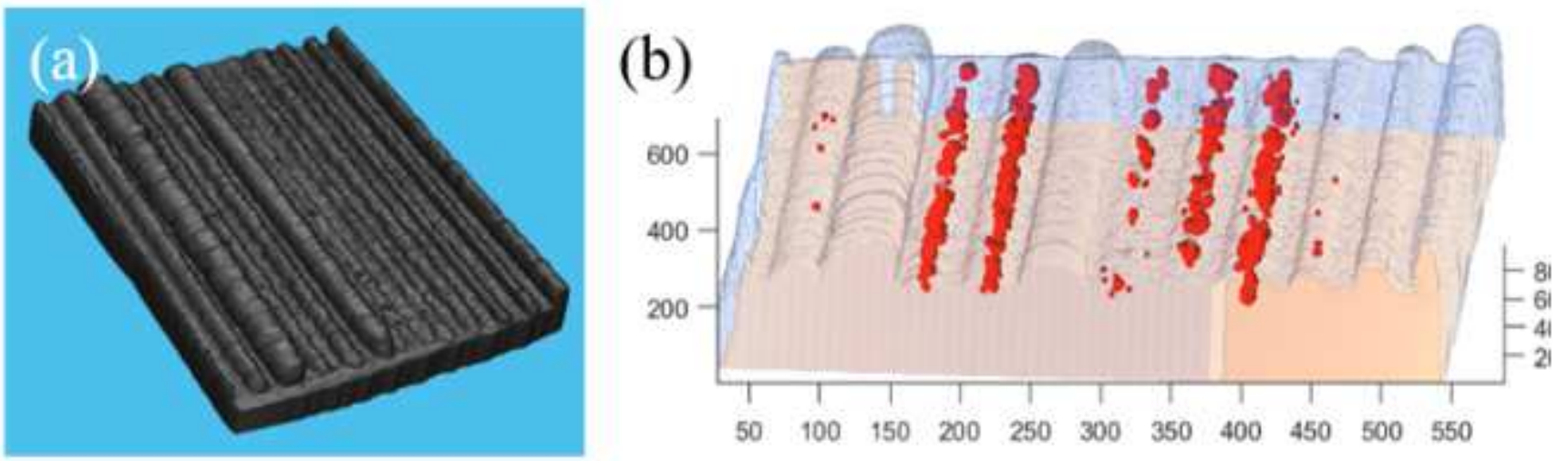

\section{Figure 23}

The CT characterization of the multi-parameter printed sample by a 3D reconstructed sample, $b$ visualized porosity distribution
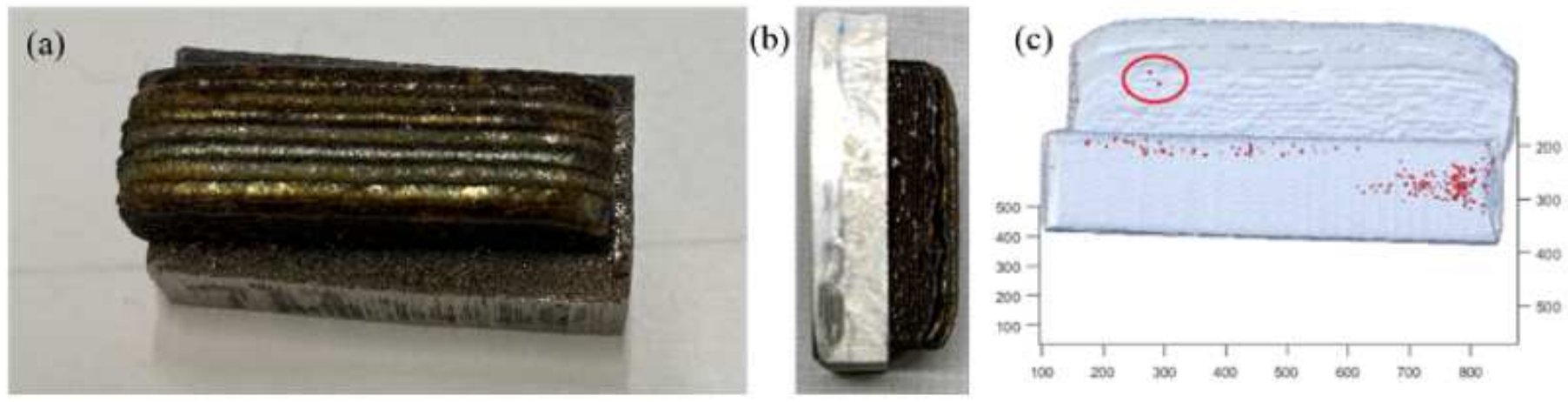

\section{Figure 24}

The X-ray characterization of samples printing on stainless steel substrate by $a$ and $b$ different views of printed sample, c porosity distribution of the printed sample

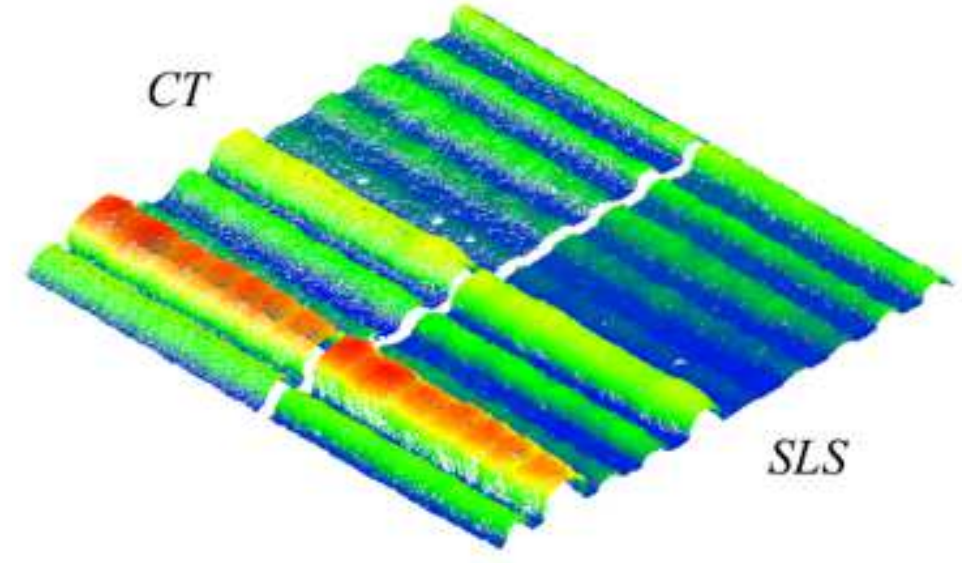

Figure 25

Surface data of Sample 2 from CT and SLS 

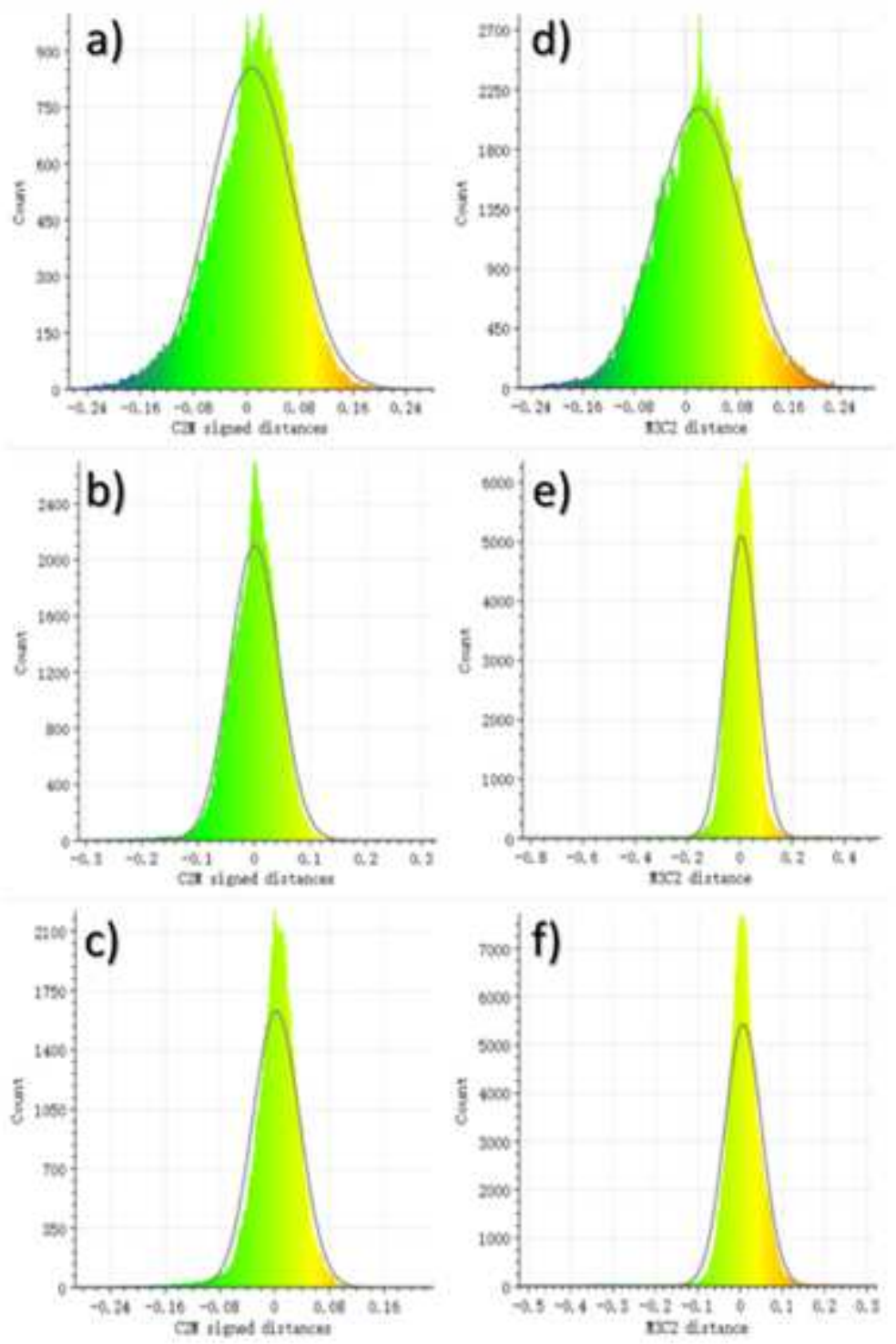

Figure 26

Histograms of the mean distance from $\mathrm{C} 2 \mathrm{M}$ and $\mathrm{M} 3 \mathrm{C} 2$ results, $(\mathrm{a}-\mathrm{c})$ the histograms of $\mathrm{C} 2 \mathrm{M}$ results for Sample 1-3, (d-f) the histograms of M3C2 results for Sample 1- 3 

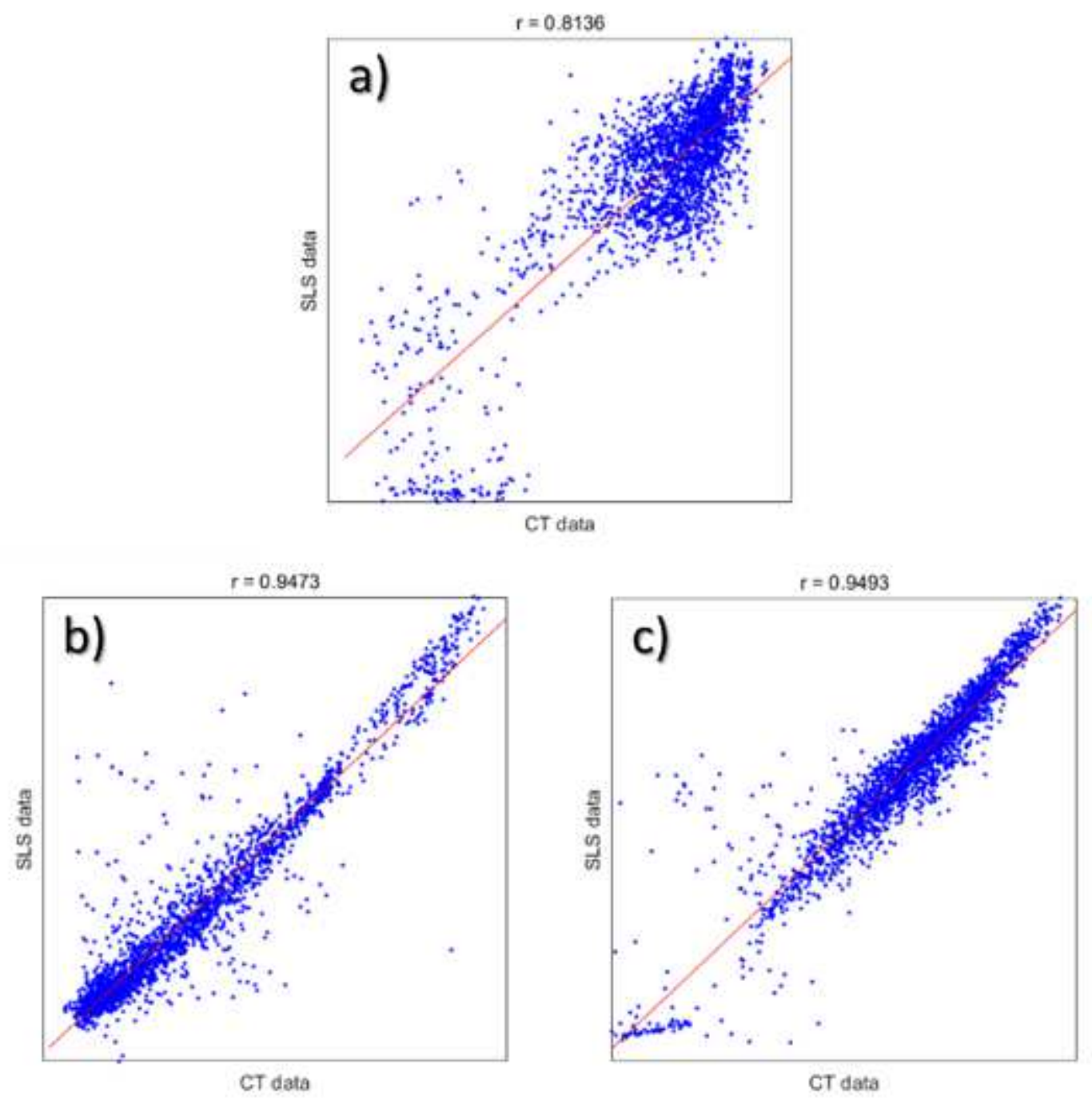

Figure 27

Scatterplot showing the correlation of two kinds of datasets for a Sample 1, b sample 2, c sample3 4 Conclusion 